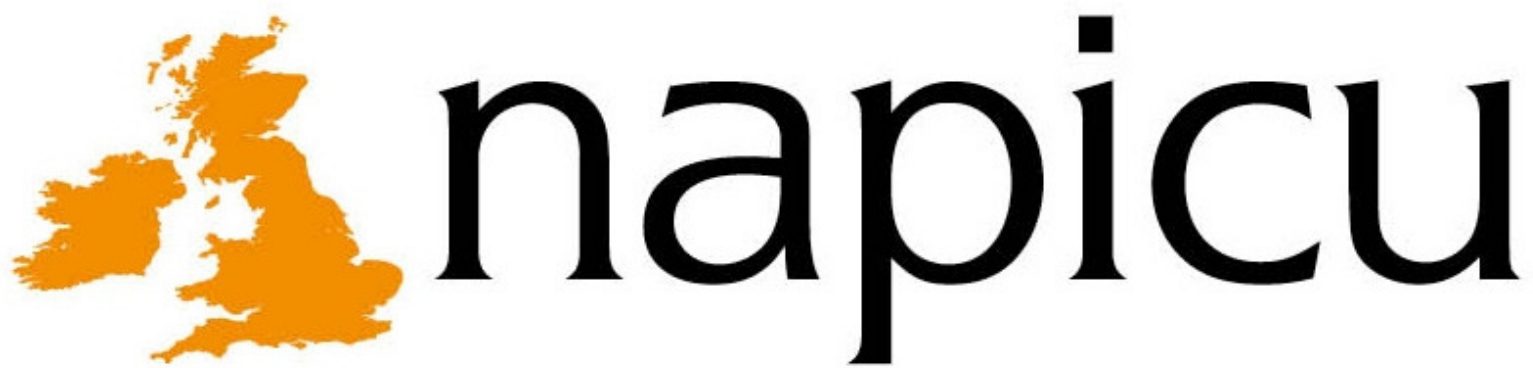

national association of psychiatric intensive care $\mathcal{E}$ low secure units

National Minimum Standards for Psychiatric Intensive Care Units for Young People

September 2015 


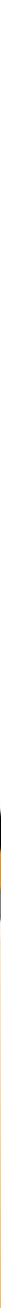




\section{National Minimum Standards for Psychiatric Intensive Care Units for Young People}

September 2015 


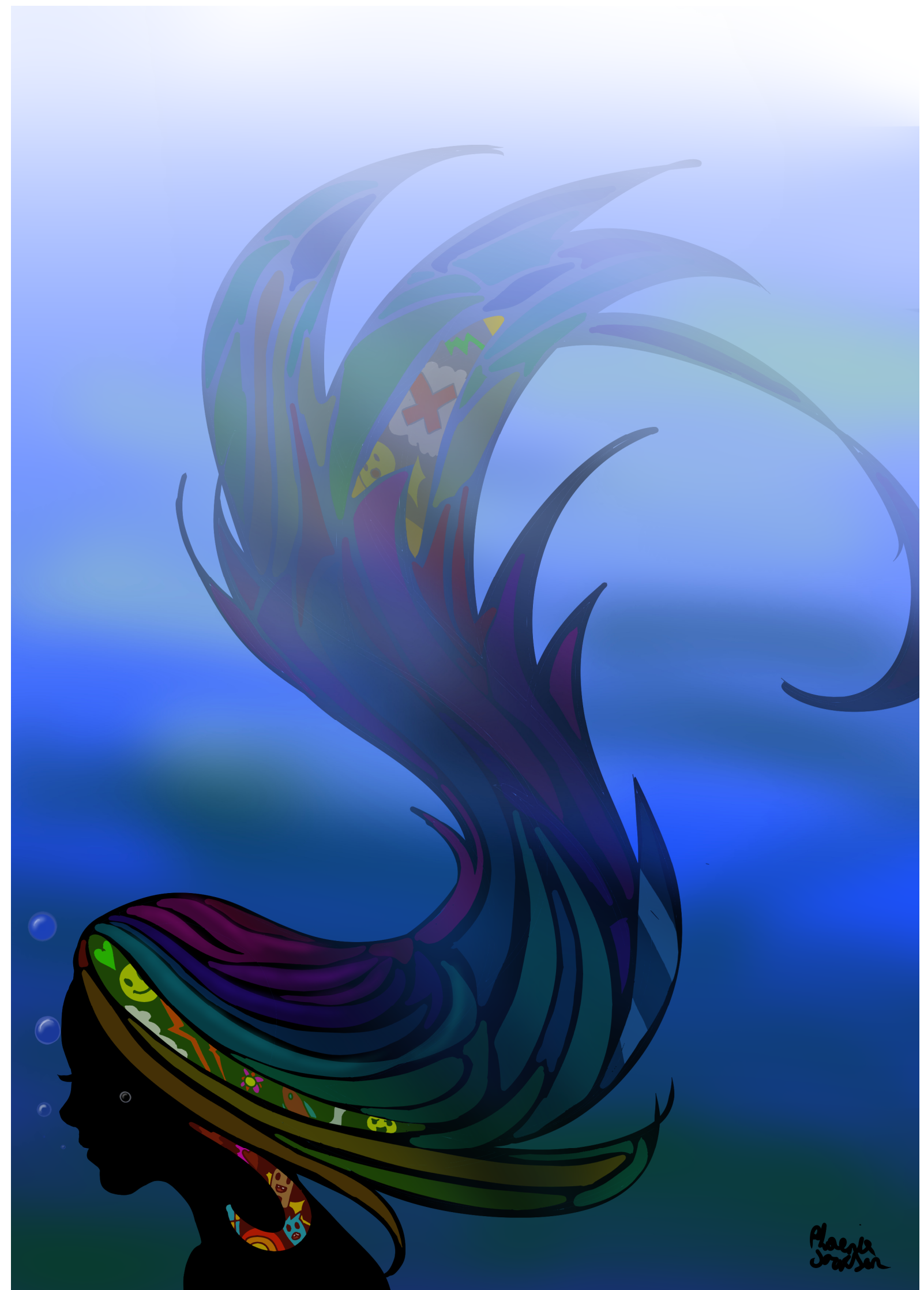

Phoenix Jackson

Candid Fallacy 


\section{Contents}

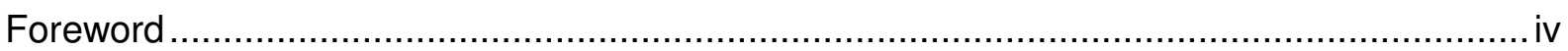

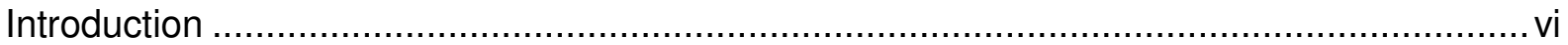

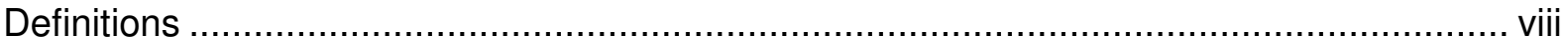

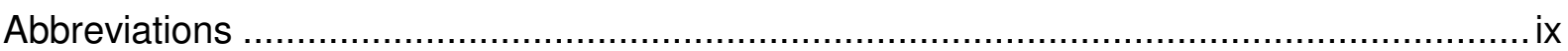

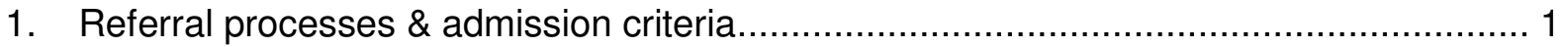

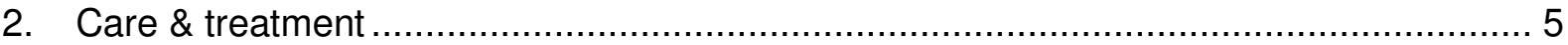

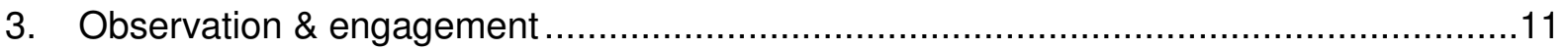

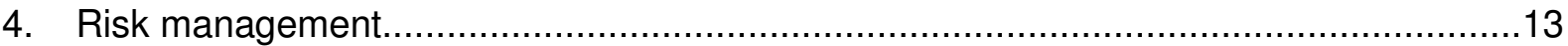

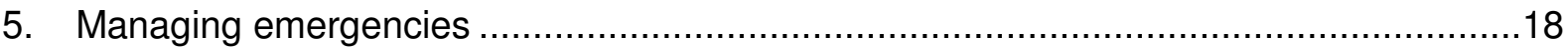

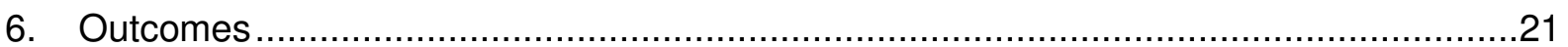

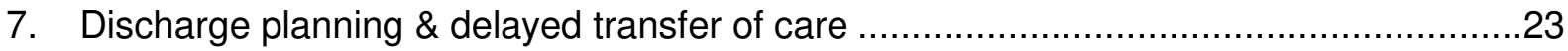

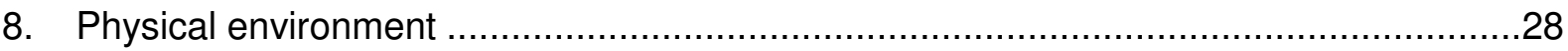

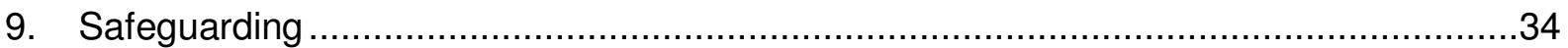

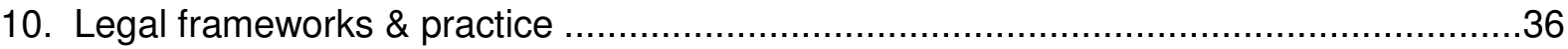

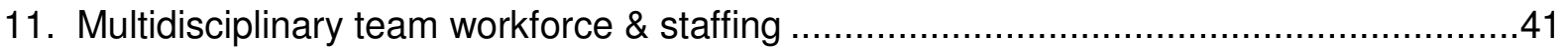

12. Staff supervision, training \& continuing professional development .............................48

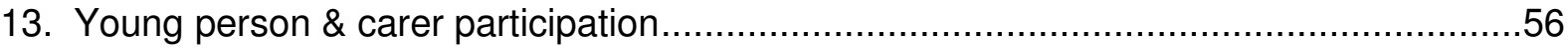

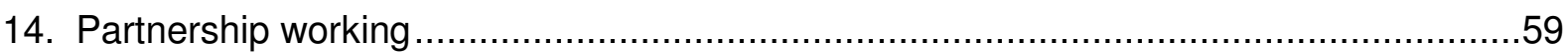

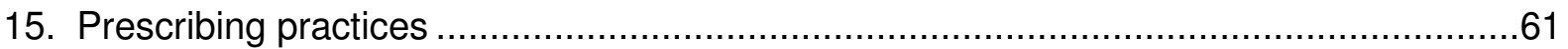

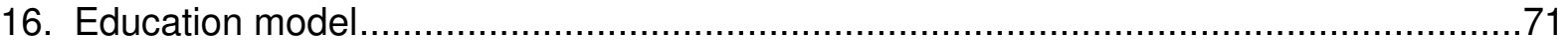

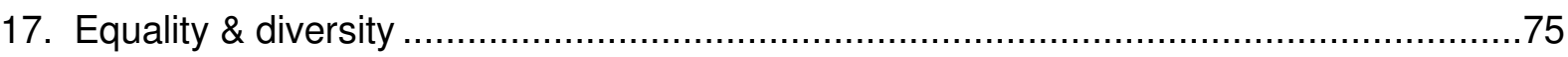

18. Quality improvement, clinical audit \& assessments..............................................

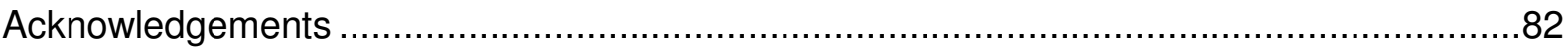

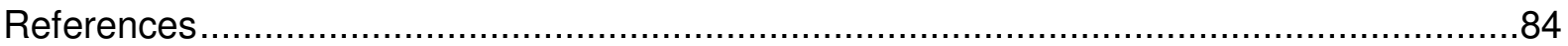

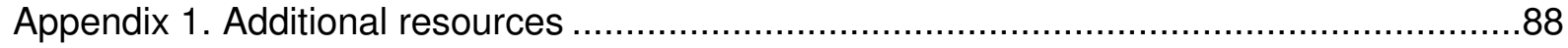

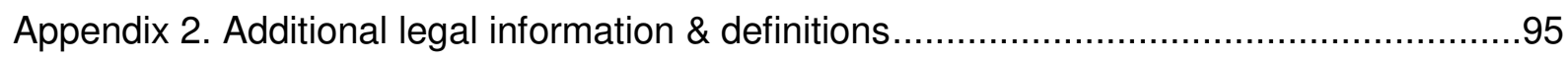




\section{Foreword}

NAPICU are to be warmly congratulated on bringing together this set of National Minimum Standards which, in the field of care and treatment of young people who present with challenging behaviours as part of their disease and dis-ease, is very much needed and long overdue.

Too often, guidance and standards for young people's services are a bolt on to those produced for adult services. In order to keep them safe and improve outcomes for young people, they must be seen, understood and supported in a developmental context.

Nowhere is this more critical than in the diverse group of young people with a range of mental illnesses, neurodevelopmental disorders and learning disability who arrive at the front door of psychiatric intensive care units for young people.

These standards are embedded, as they should be, in values-based practice and acknowledge that often young people admitted to these services have to cope not only with the distress of their acute illness but also the negative impact of adverse life circumstances. Both can result in these young people presenting to staff with extremes of challenging behaviour. Staff are tasked with keeping them safe and secure.

As with all work undertaken by NAPICU, the overarching approach taken to these standards is one of truly integrated collaborative multidisciplinary team working. This way of working demands leadership that brings clarity and routine to the lives of young people and the staff who care for them, but which also has enough 'intelligent kindness' to ensure that staff are afforded appropriate levels of support, supervision and space for individual and shared reflective thinking and practice in order to sustain their complex work with the young people.

It is important to always hold in mind that any young person is more than their illness, and that they have the right to have all the aspirations, hopes and dreams held by any other young person. So these standards help both staff and outside agencies to focus on planning their safe discharge from the intensive care unit from the day of admission, and indeed before.

Through addressing standards for referral, assessment and admission, with clear care and treatment planning, ensuring full young person and carer participation through to safe discharge, these standards also encompass management of risk and the importance of the built and relational environment together with the best evidence base for medicine optimisation and psychological therapies. These standards recognise and address the needs of vulnerable groups and have embedded in them quality improvement, outcomes and metrics.

These standards form the building blocks through which staff and services can be, as Yalom taught us, 'present and faithful' being there for young people who need, for however short a period of time, to be in a psychiatric intensive care unit.

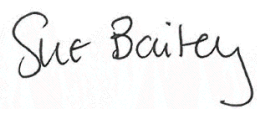

\section{Professor Dame Sue Bailey, OBE FRCPsych}

Chair, Academy of Medical Royal Colleges

August 2015 


\section{Foreword}

$\mathrm{Hi}$, we are very pleased to have been able to contribute to this first ever set of standards for psychiatric intensive care for young people.

We think that young people should be involved in making decisions about their care, because only then are we able to reach our full capacity.

We hope that everyone who works in a CAMHS PICU thinks about their practice and takes into consideration the impact they can have on our young lives. We would really like to see services which offer the right support at the right time for young people, so that fewer young people end up in hospital.

We know that the best young people's PICUs will be the ones where young people are fully involved in planning their own care so that they do not feel powerless about what is happening to them. We also think that young people should be able to make decisions about how the PICUs work. This might be by being involved in the training of staff, or being part of the recruitment of staff for example, though there are lots of other ways young people can be involved.

Please bear in mind that young people WISH to be involved in decisions about them and they actually enjoy giving their input - so PLEASE ASK US!

\section{Young People from a Gloucester Participation User Group}

August 2015 


\section{Introduction}

NAPICU is proud to publish these inaugural standards for care delivered in psychiatric intensive care units (PICUs) for young people. The increasing use of all types of mental health service by patients under the age of 18 years has received national attention in recent years. The clinical challenges presented by young people cared for in PICUs, and the variability of service provision, underlines the need for agreed and standardised care for the young people in such restrictive environments.

The extensive revision of the National Minimum Standards for Psychiatric Intensive Care in General Adult Services (NAPICU, 2014) drew on the raft of positive changes in service delivery, building design and most importantly, patient experience over the previous decade. Those standards were revised and updated by NAPICU to ensure that the quality of care continues to improve for adults. In 2015, it is evident that there is growing need for standards for PICUs which specialise in the care of young people. The number of young people requiring a PICU appears to be increasing and a shortage in provision was recognised by NHS England (2014), which committed to increasing the number of commissioned CAMHS PICU beds.

NAPICU has worked with a wide range of stakeholders from the NHS, the private and third sectors, across professional disciplines, as well as young people and their carers, to develop these specialist clinical standards. These are informed by the National Minimum Standards for Psychiatric Intensive Care in General Adult Services (NAPICU, 2014), but offer more detailed advice in areas considered vital to the care of young people in PICUs.

As the entire health economy undergoes further significant changes in the light of the Health \& Social Care Act 2012, it is well that we are reminded of Lord Darzi's aspiration that quality should become the organising factor within healthcare (Department of Health, 2008).

The purpose of the standards is threefold:

- Firstly, and most importantly, to ensure the highest quality of care for young people in Tier 4 CAMHS PICUs

- Secondly, to enable provider organisations to define and organise their services within the marketplace

- Thirdly, to provide commissioners with a framework against which to assess providers.

It is anticipated that this document should be used by both internal and external assessors. The 'Standards' set the core level of service and care; the 'Good practice guidance' sections are additional guidance for higher levels of practice. The standards contained in this document 
should be applied to all PICUs offering care to people up to the age of 18 years (usually between their 12th and 18th birthdays). Such PICUs must be within a hospital setting, and registered as such with the CQC.

This document is a significant first step in the journey towards developing the framework for what constitutes a high quality PICU environment for young people.

Stepten fercira

Dr Stephen Peirera

Chairman NAPICU

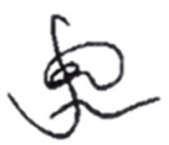

Dr Faisil Sethi

Vice-Chairman NAPICU 


\section{Definitions}

A range of titles is currently applied to PICUs which cater for young people who, for one reason or another, cannot be safely managed within general CAMHS wards. Such titles include 'psychiatric intensive care' and 'high dependency' units. In this guidance, the single title of 'CAMHS PICU' will be used to describe those units that are compliant with these standards.

CAMHS PICUs are locked wards with a small number of beds, facilitating intensive psychiatric treatment for the most acutely unwell and severely risky young people. CAMHS PICUs will, in general, offer services to both male and female patients, ensuring compliance with delivering single-sex accommodation requirements (Department of Health, 2010). It is anticipated that these PICUs will be used for the minimum possible duration in order to facilitate the principle of using the least restrictive environment. This will require a proactive approach to positive risk management, which will be outlined elsewhere in this document. Due to the locked nature of these environments, it is anticipated that the majority of the young people will be detained under the Mental Health Act 1983 as amended 2007 (MHA 1983, 2007). If not, full Mental Capacity Act 2005 assessments should have been completed and appropriate treatment contracts devised (see Chapter 10).

Young people will be admitted to the CAMHS PICU when they have been assessed as presenting with a severity of behavioural disturbance, arising from serious mental illness, which does not allow them to be safely treated within a general CAMHS acute unit. In most circumstances it would be expected that there has been effort to offer therapeutic interventions in the least restrictive available option prior to admission to the CAMHS PICU.

NHS England's draft service specification for CAMHS PICUs expects that such units '... will be provided for young people who are in an acutely disturbed phase of a serious mental illness. Young People referred will be detained under the Mental Health Act 1983 / 2007. These young people may have an associated loss of capacity for self-control, with corresponding increased risk, such that safe, therapeutic management and treatment cannot be provided within a Tier 4 CAMHS General Adolescent Service' (NHS England, 2013).

The United Nations Convention on the Rights of the Child (Article 1) defines a child as 'any person under the age of 18'. Throughout this document we have used terms 'young people' and 'young person' to describe all those under the age of 18, and they should be assumed to include both children and adolescents unless otherwise specified. 


\section{Abbreviations}

BNF British National Formulary

BNFC British National Formulary for Children

CAMHS Child \& Adolescent Mental Health Services

CGAS Children's Global Assessment Scale

CPA Care Programme Approach

CQC Care Quality Commission

HoNOSCA Health of the Nation Scales for Children \& Adolescents

MDT Multidisciplinary team

MHA 1983 Mental Health Act 1983, as amended 2007

NAPICU National Association of Psychiatric Intensive Care \& Low Secure Units

PICU Psychiatric intensive care unit

PRN 'Pro re nata' or 'as required'

QNIC ROM Quality Network for Inpatient CAMHS Routine Outcome Measurement Service

Rapid tranquillisation

SPC Summary of product characteristics 


\section{Referral processes $\&$ admission criteria}

\subsection{Rationale}

Referrals into a CAMHS PICU may cover a much broader diagnostic range than those of most adult PICUs. Young people with associated or primary developmental disorders, long-standing challenging behaviour arising from a serious mental illness, incipient psychosis and emergent personality disorder may all benefit from care within a CAMHS PICU. The individual unit's referral pathway and inclusion criteria should reflect this potential need.

\subsection{Standard}

1.2.1. A decision to treat within a CAMHS PICU should only be made when clinically warranted by the degree of presentation and associated clinical risks, and when there are identified limitations in the treatment capability of the alternative clinical provision.

1.2.2. A CAMHS PICU is intended primarily for short stay patients (up to six weeks); those requiring a longer length of stay should be considered for referral to longer stay environments including low or medium secure services as appropriate.

1.2.3. The CAMHS PICU should liaise closely with the referring service to understand:

- What interventions have already been exhausted

- What interventions will be used on step-down or return of the young person to the referring service

- The responsibilities of the referring service.

1.2.4. When admission criteria for the CAMHS PICU are not met by the young person, the CAMHS PICU should provide advice to any referring service on suitable interventions that could be considered.

1.2.5. Referring services should ensure that all available relevant clinical information about the young person is provided to the CAMHS PICU, including (see also 6.2.7-6.2.8):

- Psychiatric assessment, including regular mental state examination to inform an understanding of how an acute psychiatric illness is contributing to evolving risk

- A current and recently updated risk assessment (including the risks that have precipitated the current referral to the CAMHS PICU) that covers all domains of potential risk in order to enable an informed decision about the suitability of a 
CAMHS PICU admission, and how identified risks can be managed in this setting (see Chapter 4)

- Specialised risk assessments when indicated (e.g. Structured Assessment of Violence Risk in Youth (SAVRY) when there are concerns of a forensic nature)

- Tools used in the prediction of violence

- Specialist psychiatric assessment where needed (e.g. by a forensic child and adolescent psychiatrist or a consultant psychiatrist experienced in learning disability)

- Nursing observations

- Current assessment of physical health

- Social care assessment if any safeguarding risks have been identified

- Outcomes of any urinary drug screening assessing for substance misuse.

1.2.6. Young people with eating disorders should usually be referred to a specialist eating disorder service. However, occasionally, it may be necessary for the CAMHS PICU to consider admitting such patients, for example, when a specialist eating disorder service can no longer safely manage the young person's clinical presentation without an increase in environmental safety and security. The referring specialist eating disorder service and the PICU should consider joint working/interventions to support the young person and each other in achieving the clinical outcomes required to safely return the young person to the referring specialist eating disorder service.

1.2.7. The geographical location of the unit in relation to the young person's home or usual residence and family should be carefully considered. This is particularly pertinent in light of the sparsity of these services across the whole UK.

\section{Admission criteria}

1.2.8. There should be clear inclusion and exclusion criteria for admission to the CAMHS PICU. These should be adhered to, and a procedure established for resolving differences of opinion regarding admission or transfer.

1.2.9. Young people admitted to a CAMHS PICU should be between the ages of 12 and 18 (i.e. up to their $18^{\text {th }}$ birthday). 
1.2.10. The ages of young people currently admitted to the CAMHS PICU should be taken into consideration before a new admission is accepted (e.g. admitting a 12 year old to a ward where all the other occupants are 17 may not be the most therapeutic option).

1.2.11. Young people admitted to a CAMHS PICU should demonstrate mental health problems or a learning disability giving rise to behaviour which puts either the individual or those around them at an increased risk to a point beyond that which can be safely managed in an acute ward.

1.2.12. Young people admitted to a CAMHS PICU will generally fall into one of two broad categories:

- Complex behavioural presentations: Behaviours which are beyond the remit of a general service, which might include assaultive behaviour, absconding, and other behaviours likely to cause fear or distress to others (e.g. forensic risk, history of sexual offence). Such behaviours may arise from affective or psychotic symptoms, learning disabilities or autistic spectrum conditions.

- Serious self-harm: Behaviours that are extreme and potentially life-threatening, where the individual cannot be kept safe in an acute ward (e.g. cutting and use of ligatures).

1.2.13. Young people should be detained under a relevant section of the MHA 1983 (see 10.2.16).

1.2.14. A clear and consistent pathway for care within the CAMHS PICU must be in place. This is important as it will assist in reducing unnecessary variations in patient care and outcomes. It should support the development of care partnerships, and empower the young person and their family and/or carers by developing knowledge and skills for the longer term management of their difficulties.

1.2.15. The development of the CAMHS PICU care pathway should be based on:

- Evidence-based practice and guidance (e.g. NICE guidelines, Royal College of Psychiatry guidelines)

- The experiences of the young person and their family and/carers (e.g. patient outcomes, satisfaction surveys)

- Professional experience and the judgement of the clinical team.

1.2.16. The CAMHS PICU care pathway should incorporate local and national guidelines. 
1.2.17. Organisations need to work to develop clear care pathways for patient care. Effective implementation of this care will be affected by:

- Good collaboration with the young person, their family and/or carers and professionals

- Ward staffing levels and mix of skills

- Thoughtful approach to reviewing the symptoms or presentations, and the appropriate treatments and interventions

- Goals and outcomes should ideally be agreed with the young person and their family and/or carers, and developed using an inter-agency evidence base (e.g. the goal of stabilisation and reduction in risk versus cure and elimination of risk).

\subsection{Good practice guidance}

1.3.1. Ideally, a young person should not be accepted for treatment in the CAMHS PICU unless there is clear pathway or provision to transfer them to a more appropriate clinical environment as warranted by the clinical or risk profile (e.g. a medium secure unit, a low secure unit, a general CAMHS ward or a criminal justice setting).

1.3.2. A clear purpose of admission to the CAMHS PICU should be understood universally within the acute care pathway and be supported by clear referral mechanisms and clinical support structures. An estimated date for transfer back to less intensive provision should be agreed during the admission process and reviewed at least weekly during the regular MDT meeting. 


\section{Care \& treatment}

\subsection{Rationale}

The CAMHS PICU service should aim to provide young people and their families and/or carers with an intensive multidisciplinary, therapeutic and educational program whilst admitted to the PICU. This program should involve all relevant family members and friends, where appropriate and logistically viable. The program should involve all relevant agencies and professionals from the point of admission. A clear 'stepped model of needs' should be established based on risk to self and others, and level of functioning. This step up and down process should be clear to all those involved, including the young person.

The decision to admit a young person into a CAMHS PICU is not taken lightly and often comes after many failed interventions. For many young people, the CAMHS PICU provides stability, boundaries and security that have not always been achieved in their lives prior to admission.

\subsection{Standard}

2.2.1. The aim of the admission to the CAMHS PICU must be clear to the young person and their family and/or carers.

2.2.2. The pathway should include treatments and interventions to facilitate the rapid stabilisation and reduction of high risk behaviours that exclude the young person from functioning in less restrictive environments and the community. Thus, the primary focus of treatment should be on helping the young person to reduce the frequency and severity of high risk destructive and self-destructive behaviours, while reducing the need for high frequency monitoring and containment. As risk behaviour reduces, the focus on independent functioning should increase, thus facilitating a step-down to generic open wards and discharge.

2.2.3. Each individual care plan should provide a multidisciplinary outline of anticipated care, placed in an appropriate timeframe, to the young person, their family and/or carers, and other professionals. This should be focused on a specific condition or set of symptoms and individualised to enable the patient to move progressively through a clinical experience to positive outcomes.

2.2.4. It is expected that the majority of young people will complete their treatment on a CAMHS PICU within six weeks.

2.2.5. The CAMHS PICU care pathway should outline the optimum treatment sequence and timing of interventions by clinicians, nurses, other professionals and agencies. 
2.2.6. Once the CAMHS PICU care pathway has been established for a particular group of symptoms (e.g. severe depression, severe self-harm) it can act as a standard for the delivery of patient care, which can be monitored, streamlined and improved.

\section{Assessment}

2.2.7. As the aim of a CAMHS PICU admission is to rapidly stabilise and reduce high risk behaviours that exclude the young person from functioning in less restrictive environments and the community, a timely MDT assessment and formulation is essential. Such assessments should include information gathered from all available sources including:

- Schools, colleges and other education establishments, and employers where appropriate

- Previous and current primary care services, mental health services and young offenders' institutions, including previous formulations/diagnosis, treatment/interventions, responses and compliance with treatment/interventions

- Previous risk assessments and profiles, plus trauma and assault histories

- Developmental history, family history and current support networks

- Social care workers

- Family and/or carers

- Any other source, including voluntary and community services, where appropriate.

2.2.8. The MDT should review and/or undertake the following assessments as soon as possible after admission:

- Psychiatric assessments (this should include mental state and psychiatric diagnosis, treatments and responses to date)

- Psychological assessments (e.g. cognitive and personality assessments)

- Nursing assessments (which should include engagement with professionals and peers, social functioning, risk assessments and physical health assessments)

- Occupational therapy assessments (e.g. Model of Human Occupation (MOHO) range, sensory profile, assessing daily living skills and adaptive functioning skills)

- Family/systemic assessment (e.g. an assessment of family functioning and the supporting network). 


\section{Formulation/diagnosis}

2.2.9. All of these suggested assessments should be used to identify the goals of the admission, to predict any ongoing needs and risks to be addressed in the community; and should be summarised in the formulation. It is recommended that the formulation should be shared with the young person, their family and/or carers, and other professionals involved in the young person's care. The formulation will underpin the care plan and intensive treatment that the young person receives whilst in a CAMHS PICU. It may inform the step-down, transition, discharge and aftercare plans (see Chapter 7). Therefore, it should be well structured, easy to follow and easy to understand. One suggested approach is the four Ps:

- Predisposing factors: The historical factors, developmental history etc. that may be the foundation for the young person's current difficulties

- Precipitating factors: The factors that may have acted as triggers or the catalysed for the current crisis (e.g. death of a loved one, break up of a relationship)

- Perpetuating factors: What factors maintain the difficulties, keep them going (e.g. a volatile relationship)

- Protective factors: What strengths the young person and their family and/or carers have.

\section{Interventions/treatments}

2.2.10. As the aim of a CAMHS PICU care pathway is to rapidly stabilise and reduce high risk behaviours, the interventions and treatments informed by the formulation and care pathway, will need to be time limited and intensive. Thus, the young person and their family and/or carers may require multiple sessions per week. The treatments and interventions should primarily address the high risk symptoms and behaviours that exclude the young person from functioning in less restrictive environments and the community.

2.2.11. The CAMHS PICU should have clearly defined standard operating procedures (SOPs) in place for commonly used interventions, such as seclusion or restraint.

2.2.12. Wherever possible programmes of therapy commenced prior to admission to the CAMHS PICU should continue.

2.2.13. Daily MDT handovers should be structured, with a focus on risk and safety. There should be clear structures for communication to the MDT of any identified concerns. 
2.2.14. Using evidence-based practice (e.g. NICE guidelines) the CAMHS PICU team should be able to provide the following treatments and interventions as needed:

- Pharmacological and biological interventions (see Chapter 15)

- Individual psychological therapy.

2.2.15. Psychological therapies may be offered by a range of staff including psychologists, nurses and therapy staff. Those delivering a therapy should be suitably trained and appropriately supervised.

2.2.16. Clinicians should check the current evidence base to inform their treatment plan. A range of therapies should be available, to be started or continued as needed; e.g.:

- Cognitive behavioural therapy (CBT) (e.g. trauma focused, mentalisation)

- Interpersonal psychotherapy (IPT)

- Dialectical behaviour therapy (DBT)

- Cognitive analytical therapy (CAT)

- Brief psychodynamic interventions

- Group psychological therapies, e.g.:

Mentalisation based group

Mindfulness group

DBT group

CAT group

Interpersonal relationship group.

2.2.17. A range of therapeutic activities should be available for young people, both in the weekday working hours and in the evenings and at weekends (College of Occupational Therapists, 2012). Such therapies should be delivered by registered healthcare professionals including nurses and occupational therapists with specialist skills working with young people in acute psychiatric inpatient care, and support staff (e.g. an activities co-ordinator). Suggested interventions may include:

- Maintaining good physical health

- Maintaining good diet and fluid intake

- Monitoring medication effects

- Sleep hygiene

- Personal hygiene 
- Assessment of, and assistance with, daily living skills

- Physical exercise and physical activities

- Collaborative problem solving

- Promoting pro-social behaviour

- Hobbies, arts and crafts

- Sporting and leisure activities

- Drama, art and music groups

- Mindfulness, distraction and relaxation techniques

- Promotion of acquisition of new skills.

2.2.18. Suggested systemic or family-based interventions include:

- Mentalisation-based family therapy

- Functional family therapy

- Parent skills groups

- Structural or strategic family therapy

- Psychodynamic family therapy

- Psychoeducation.

2.2.19. For educational interventions, see Chapter 16.

\section{Physical health}

2.2.20. Young people in a CAMHS PICU are also vulnerable to physical health illnesses and disturbances, and the following should be taken into account:

- Their mental state, developmental or learning difficulties may not allow them to communicate to family, carers or staff in a way in that allows prompt appropriate assessment and treatment

- Their agitated state may temporarily obstruct a thorough physical examination

- Pre-existing medical conditions are at risk of being overlooked and mismanaged

- Young people are considerably more vulnerable to the effects of psychotropic medication, including metabolic syndromes and severe clinical pictures i.e. neuroleptic malignant syndrome (see Chapter 15).

2.2.21. The CAMHS PICU should have thorough protocols to ensure that physical health needs of young people are adequately met. 
2.2.22. A physical examination, including a neurological examination should be carried out for all patients at the earliest opportunity after admission.

2.2.23. From the point of admission, and before that where appropriate, a thorough differential diagnosis should be sufficient to identify any physical health factors that may contribute to the presentation; e.g. toxic, encephalitic, metabolic etc.

2.2.24. The medical and nursing staff on a CAMHS PICU should be trained in early detection, management and monitoring of such conditions, including emergencies.

2.2.25. The CAMHS PICU will benefit from establishing effective communication with the young person's general practitioner. This will contribute to continuity of care with regards to physical health before and after each admission.

2.2.26. It is important that the CAMHS PICU is geographically close to a paediatric service such as a district general hospital paediatric ward. It would be advisable to establish close links with such a service; i.e. to find a nominated paediatrician with whom the unit can liaise as needed. Periodic joint teaching events between services are advisable, to contribute to increased standards and collaboration.

\subsection{Good practice guidance}

2.3.1. Access to a wide range of staff from a number of key disciplines is essential to deliver optimum treatment for young people (see Chapter 11). The MDT will have an essential role within the care pathway, in promoting optimum engagement with treatment and interventions. It will also be essential to promote involvement of the young person and their family and/or carers in construction and evaluation of the care pathway. 


\section{Observation \& engagement}

\subsection{Rationale}

The practice of nursing observation is designed to ensure the safety and well-being of both patients and staff. The more general practice of engagement relates to optimising the opportunities for therapeutic intervention to occur.

The NICE guidance for the management of disturbed or violent behaviour outlines standards for both policy and practice in inpatient settings (NICE, 2015a). The guidance describes the following levels of observation:

- Low-level intermittent: once every 30-60 minutes

- High-level intermittent: once every 15-30 minutes

- Continuous: within eyesight or arms' length of a designated one-to-one nurse

- Multiprofessional continuous: within eyesight of two or three members of staff and at arms' length of at least one member of staff.

Observation remains a core intervention in inpatient settings and is routinely used in CAMHS PICUs in order to manage behaviour which is likely to lead to injury of either the young person or those around them.

\subsection{Standard}

3.2.1. Policies should comply with the standards set out in current NICE guidance (NICE, 2015a). In addition they should consider clinical presentations where the use of increasing levels of observation may be counter-therapeutic.

3.2.2. All clinical staff should be trained in the use of observation, including particular factors associated with self-harm.

3.2.3. Particular consideration should be given to the needs of the young person when providing higher levels of observation; experience of previous trauma may mean that such observations could be counterproductive.

3.2.4. The ward programme should demonstrate a range of organised activities seven days a week in which staff can engage with young people.

3.2.5. Each young person should be provided with the opportunity for one-to-one time with a member of staff every day.

3.2.6. Each young person should have an individualised security plan to include selfmanagement strategies. 
3.2.7. Observation recording (at all levels) should be subject to routine audit, including the offering of one-to-one time on each shift.

3.2.8. When undertaking observation, staff should actively attempt to positively engage with the young person.

3.2.9. Observation level reviews should occur regularly and be fully documented in the health record. Reviews must ensure that the emphasis is to work with the young person at the lowest possible level of restriction, i.e. the assumption should be that 'general observation' is the default level and should only be increased if risk assessment indicates it to be necessary.

3.2.10. Observation should be undertaken by all clinical staff and should not be seen as the exclusive domain of the non-registered practitioners.

\subsection{Good practice guidance}

3.3.1. The unit policy should demonstrate the participation of young people in its development and should promote a culture of creative approaches to ensure that the principle of least restrictive practice applies.

3.3.2. Staff training and supervision should explore the dynamic and interpersonal characteristics of observation noting the relationship between staff and young people and the intuition which arises from it as a critical component of keeping people safe from harm. 


\section{Risk management}

\subsection{Rationale}

CAMHS PICU services are by definition reserved for young people presenting with risks to themselves or others that cannot be managed in an open acute setting.

Good risk assessment and management are integral to a CAMHS PICU service; they should be exemplary and inform decision making throughout the process of admission, treatment and discharge. Particular risks to be considered in the context of an acute mental illness are selfharm and other self-destructive or suicidal behaviour, aggression, fire-setting, sexually disinhibited behaviour, absconding, drug and alcohol misuse, and self-neglect. Additionally, issues relating to interactions between young people on a CAMHS PICU, such as vulnerability and bullying, need to be considered.

\subsection{Standard}

\section{Risk assessment}

4.2.1. Risk assessment should be a dynamic, continuous, multidimensional process that starts at the point when a young person is being assessed for a potential admission to a CAMHS PICU. This comprehensive risk assessment should be completed.

4.2.2. When making a referral to a CAMHS PICU, all relevant clinical information should be provided, including a current risk assessment. This enables the CAMHS PICU team to make informed decisions about how to manage the identified risks in this setting if the admission is agreed.

4.2.3. The risk assessment should consider risk in the short-, medium- and long-term, and cover all domains of potential risk.

4.2.4. The risk assessment should have a multiagency approach, consisting of regular liaison with appropriate external agencies (e.g. social care and youth offending teams) is essential to ensure that the understanding of risk is comprehensive and shared.

4.2.5. The risk assessment should make use of specialised tools when indicated (e.g. Structured Assessment of Violence Risk in Youth (SAVRY) when there are concerns of a forensic nature about a young person). 
4.2.6. The risk assessment should be considered alongside any:

- Psychiatric assessment, including regular mental state examination to inform an understanding of how an acute psychiatric illness is contributing to evolving risk

- Specialist psychiatric assessment where needed (e.g. by a forensic child and adolescent psychiatrist or a consultant psychiatrist experienced in learning disability)

- Regular assessment of physical health

- Social care assessment where child protection risks have been identified

- Results of any search of the young person for possessions that may lead to an increase in risk (e.g. sharps and illicit substances)

- Educational assessment.

\section{Ongoing assessment \& management of risk}

4.2.7. As far as possible, a proactive approach to risk should be adopted, in which potential risks are anticipated and addressed in advance.

4.2.8. A meaningful risk management plan should be developed, which considers the dynamic nature of risk, addressing each risk along its multiple dimensions.

4.2.9. Important risk considerations within the CAMHS PICU include:

- Common aggravating factors:

Unsupervised time/leave/absconding

Concurrent substance misuse

- Specific risks/aggravating factors:

Self-harm/other self-destructive or suicidal behaviour (including unsupervised access to common areas)

Access to sharps or other items with potential to cause harm or be used as weapons

Ligature points

Furniture \& appliances (e.g. door handles, plugs, cords etc.)

Windows

Toilet privacy

Access to lighters, matches and inflammable items

Self-neglect through lack of access to facilities for self-care.

4.2.10. Routine methods may be needed to safely manage fluctuating risks, such as increasing nursing observations (e.g. one-to-one observations). 
4.2.11. Risks may constantly change, therefore these and their management should be reviewed by the consultant and wider MDT at least weekly, and plans should be stepped up or down as needed.

4.2.12. The CAMHS PICU may have a formally agreed list of contraband items. Patients and their family and/or carers should be informed of which items are prohibited on the unit. A full search of each young person and their possessions should be conducted before admission and on return from any periods of leave. All visitors should be informed of items that cannot be brought onto the CAMHS PICU.

4.2.13. Young people may be subject to urine drug testing on admission and on return from a period of leave if there are concerns that they have misused substances. For young people with a known or reported history of extensive substance misuse, a more detailed toxicology examination to test for substances not detectable on routine urine screening may be necessary.

4.2.14. The CAMHS PICU should aim to involve the young person in their risk assessment and management at every point possible from before admission to after discharge (see Chapter 13). The young person should be seen as a partner in risk assessment and management. The nature of the difficulties that young people present with in a CAMHS PICU, as well as their age, will often make it hard for the interaction between staff and patient to be a true partnership, but it is important to strive to achieve this and to maximise the potential of establishing a good relationship and an inclusive approach.

4.2.15. On occasions where there is an acute escalation in risk of harm to self or others:

- De-escalation strategies should be used (e.g. distraction, verbal prompting and redirection, time in a lower stimulus environment such as a quiet room, use of weighted blanket/jacket as appropriate)

- Use oral PRN medicine

- Use physical restraint and/or intramuscular RT if risk is severe and oral medication is refused, as per the organisation's RT policy

- In cases of severe violent behaviour unrelated to mental illness, consider involving police/criminal justice system.

4.2.16. Incidents occurring within the CAMHS PICU should be reported according to the organisation's serious untoward incident (SUI) policy. Additionally there should be:

- A serious case review investigation (if required) with the dissemination of lessons learned

- Audit, outcomes monitoring and quality improvement

- Feedback from key stakeholders, including young people and their families and/or carers. 


\section{Cultural factors}

4.2.17. Cultural factors play an integral part in risk and different factors will impact on risk from both the young person's and the service's perspective, and it is important to take these into consideration. Examples of cultural factors that may affect risk from a young person's perspective include:

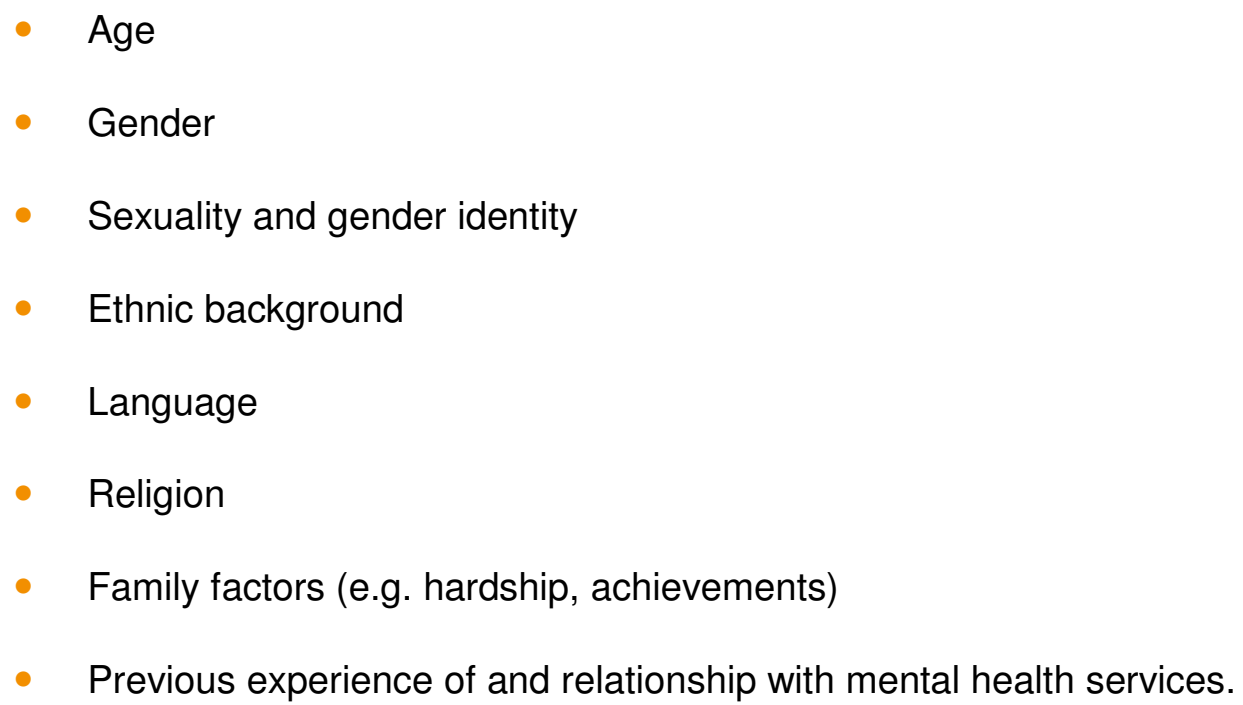

4.2.18. Staff should learn about the strengths that each young person and their family and/or carers have, and relevant protective factors. These will include strong relationships and engagement with an educational programme. This will play a crucial role in strengthening and promoting health and recovery, thus reducing risk.

4.2.19. Characteristics of the staffing team that might impact on risk include:

- Actual and perceived staff morale

- Staff turnover rate

- Permanent/bank staff ratio

- Staff/patient ratio

- Previous history of severe incidents or fatalities

- Hierarchy within and between disciplines

- Ethnic make-up of the staff group

- Gender ratios. 


\section{Risk \& interfaces}

4.2.20. The interfaces between the CAMHS PICU and the services that young people are admitted from and discharged or transferred to are highly relevant to risk assessment and management.

4.2.21. A young person admitted to a CAMHS PICU may be discharged to a more or less restrictive setting according to risk. The transfer to a more restrictive or secure setting is normally informed by an escalation of actual or perceived risk. The MDT should assess each case and reach a decision according to the best interest of the young person, as well as the safety of other young people and staff. Protracted assessments or delays in bed finding will cause uncertainties for the young person which may increase certain risks (see Chapter 7).

\subsection{Good practice guidance}

4.3.1. The CAMHS PICU will benefit from having a good knowledge of their local, regional and national options when it comes to interfaces with other services. Establishing good working relationships with these services will make transitions more effective and less risky.

4.3.2. Risk assessment should be a dynamic, continuous, multidimensional process.

4.3.3. Elements of risk assessment should include structured and sometimes specialist risk assessment tools, nursing observation, psychiatric, psychological and social care assessment, multiagency liaison, searching and drug screening.

4.3.4. Where possible CAMHS PICUs should work together across organisational boundaries to share learning about untoward incidents.

4.3.5. An antecedent, behaviour, consequence (ABC) approach may be helpful in understanding what is driving and maintaining risky behaviours in some young people (e.g. learning disability).

4.3.6. It is paramount that every CAMHS PICU remains up to date with the risk assessment literature (evidence-based or otherwise) and has regular in-house teaching sessions about it to appraise such literature, and modify and apply it to the specific needs of the unit.

4.3.7. Risk management should follow the dimensions identified through comprehensive assessment, be proactive and informed by an MDT approach.

4.3.8. Good management of risk at an organisational level involves relevant staff training, clear policies, structures for reporting and responding to incidents, regular audit activity, outcomes monitoring and quality improvement processes with a focus on safety. 


\section{Managing emergencies}

\subsection{Rationale}

CAMHS PICUs will be required to respond to a wide variety of behaviours which may include young people attempting to harm themselves or others, or to damage property. The severity of such behaviours may occasionally be deemed to be a psychiatric or medical emergency and require active management from the clinical team.

The standards elsewhere in this document aim to generate a ward milieu which minimises such emergencies, however it is still possible that such events will occur and the service will need to be able to respond therapeutically.

Restrictive practices (which may include restraint) are part of a hierarchy of response to behaviour and must only ever be used when all other reasonable avenues for resolving the situation without use of force have been exhausted. Providers are required to develop practice in line with the principles laid out in Positive and proactive care: reducing the need for restrictive interventions (Department of Health, 2014); i.e. to use the least restrictive suitable intervention.

\subsection{Standard}

5.2.1. All CAMHS PICUs must have a procedure for the prevention and management of violence and aggression, which requires staff to be trained in evidence-based and/or recommended approaches to reduce the risk of a need for restrictive interventions (such as restraint). All staff involved in restraint should have undergone specific physical intervention training aimed at CAMHS and robust governance arrangements should be in place to monitor and measure efficacy and outcomes of interventions (see Chapter 12).

5.2.2. There must be a procedure for medical emergencies which is consistent with the context of the CAMHS PICU, considering the difficulties which can emerge in transferring care to the acute medical setting and mindful of the potential for countertherapeutic re-enforcement of self-harm.

5.2.3. CAMHS PICUs must operate a process of assessment which enables an understanding of young people, so that individualised behaviour-support and security plans can be developed; the latter should include self-management strategies.

5.2.4. Policies, training and individualised care should all reflect the need for careful use of restrictive practices which may have a particularly negative effect due to a young person's past experience of trauma and abuse. 
5.2.5. Due to the risks associated with restraint, all episodes must be recorded in terms of duration, techniques used and personnel involved. This should be subject to routine monitoring and audit.

5.2.6. All staff should be trained in non-prone restraint techniques.

5.2.7. Each young person's care plan should aim to reduce their need for restraint. Where planned restraint is required exceeding the above, a completed risk assessment and rationale must be available for scrutiny, informed by the MHA 1983 Code of Practice (Department of Health, 2015).

5.2.8. All CAMHS PICUs must have a procedure which ensures the attendance of staff trained in Immediate Life Support (ILS) (Resuscitation Council (UK), 2014) at all episodes of restraint and medical emergencies.

5.2.9. The ILS response may include staff from other parts of the hospital and where this is the case there should be regular drills to ensure the timely arrival of staff and emergency equipment (e.g. defibrillator, oxygen cylinder etc.).

5.2.10. All emergency equipment should be checked weekly and be subject to any other checks required by the manufacturer and local policy.

5.2.11. All interventions should be age-appropriate and local policies should reflect the differing needs of different age groups (see 15.2.26-15.2.34 for RT).

5.2.12. Where seclusion is used, it should be undertaken in accordance with the MHA 1983 Code of Practice (Department of Health, 2015) and should be used in the context of the young person's behavioural support plan.

5.2.13. After all incidents where restrictive practices such as restraint, RT or seclusion have been employed, the young person should be given the opportunity to provide feedback in a de-brief session with a member of staff.

5.2.14. The police should be involved if the risks to staff or others is deemed unmanageable and there is perceived or actual harm.

5.2.15. After all incidents where restrictive practices have been employed, and on other occasions where it is felt to be helpful, there should be a team review of the incident to enable reflection and learning regarding the care of the individual young person and wider services. 


\subsection{Good practice guidance}

5.3.1. Techniques for physical intervention that are used on adults are not always suitable for use on young people, and there is a risk of injury to both the young person and staff. It should be remembered that a young person is not necessarily less strong than an adult in a similar situation, and being smaller may actually be more difficult to restrain effectively. CAMHS PICUs should take opportunities to be involved in the development of empirical evidence and published knowledge in this area.

5.3.2. An independent advocacy procedure which assesses every case of physical restraint, and any patterns of use, can be a useful tool for analysing and improving the techniques used (NICE, 2015a). This should include feedback from young people. A review and de-brief should not be viewed as a negative reflection on things that went wrong, but as a learning tool to create a valuable internal evidence base. 


\section{Outcomes}

\subsection{Rationale}

Through the development of the Children and Young People's IAPT programme, outcome measures are now being used in community services (see Appendix 1); these should continue throughout the young person's treatment in hospital. Data is most commonly collected at the start and end of any treatment (e.g. individual or group-based therapy), but can also be used to explore the impact of a particular intervention and plan future treatment if collected whilst treatment is ongoing. There are a number of benefits of this for the CAMHS PICU, including informing treatment and resource planning, improving therapeutic effectiveness, staff motivation and providing accountability to all stakeholders. Standardised and validated outcome measures allow the CAMHS PICU to compare the progress of their inpatients with those of both similar and different services, and thus evaluate the effectiveness of treatment.

\subsection{Standard}

6.2.1. Outcome measures should be used to monitor the effectiveness of the individual agreed care plan for each young person.

6.2.2. Using a standardised and validated outcome measure on admission, allows a comparison of a young person's current symptoms and functioning with those of other young people of similar age and background. The results should then be used to plan appropriate required resources and therapeutic needs from an understanding of the young person's stage of illness and recovery. The process also offers an opportunity for the MDT members to engage with the young person and show that their needs are being listened to.

6.2.3. Outcome measures collected during and at the end of treatment, provide an indication of progress and a measure of the impact of that treatment on a young person. They should be used to plan any further required treatment.

6.2.4. Certain measures should be repeated regularly (e.g. HoNOSCA and CGAS 6weekly). Co-ordination with referring and receiving agencies should ensure that regular measures are continued from before and after admission. 


\subsubsection{Outcome measures should be used to:}

- Track progress in achieving the treatment goals identified by the MDT

- Continuously improve the treatment interventions delivered

- Identify problems and difficulties in the effectiveness of the intervention

- Provide a new focus and ideas for a young person who has received several treatments prior to admission

- Communicate data regarding the progress of the young person to all key stakeholders in an easy to understand format (e.g. young person, family and/or carers, MDT, referring teams, the community and wider society).

6.2.6. Multiple perspectives from the clinician, young person, family and/or carers, and teachers should be obtained regularly and recorded; as a minimum on admission and discharge, and additionally at care planning reviews.

\subsection{Good practice guidance}

6.3.1. The Quality Network for Inpatient CAMHS (QNIC) is part of the Royal College of Psychiatrists and aims to demonstrate and improve the quality of inpatient CAMHS. The network sets standards for inpatient care and uses an audit cycle of self- and peer-review. The network also provides a way of services sharing best practice with each other, which is particularly important when units are often geographically isolated. QNIC offers a routine outcome measure service (QNIC ROM), which supports services to collect and analyse data. The data can then be compared with that of other services nationally. It is highly recommended that CAMHS PICUs seek membership and use the QNIC ROM service. QNIC ROM includes both general and specific diagnostic tools (see Appendix 1).

6.3.2. It is good practice to seek verbal consent from the young person before asking them to complete an outcome measure and to provide clear information in an understandable format about the reasons for using the measure, how the data will be used and how to complete the measure correctly.

6.3.3. Tools specific to specialist units should be selected based on evidence in the literature and further consultation with experts in each of the specialist groups (e.g. eating disorders). See Appendix 1 for suggested resources. 


\section{Discharge planning \& delayed transfer of care}

\subsection{Rationale}

The final stage of the CAMHS PICU care pathway should be to afford a smooth transition or step-down into a less restrictive environment. Careful discharge planning is required at an early stage to avoid a delayed transfer of care (DToC), i.e. when a young person is ready to move from a CAMHS PICU to another setting, but a bed is not available. Delays in transfer, both between wards and back to the community, can lead to disappointment and frustration which may have a severely negative impact on any improvements in a young person's condition made during admission to CAMHS PICU.

A patient is ready for transfer when (NHS England, 2015):

- A clinical decision has been made that the patient is ready for transfer and

- A multidisciplinary team decision has been made that the patient is ready for transfer and

- The patient is safe to discharge/transfer.

A successful transition is underpinned by a comprehensive assessment of need, clear goals and defined outcomes. The views and wishes of the young person are key to a successful transition. This works best when the patient is given the opportunity to be heard and contribute to the assessment of their need and their future plans (Kane, 2008).

\subsection{Standard}

\section{Discharge planning}

(see also Chapter 4)

7.2.1. Discharge planning should begin at the point of admission or as soon as possible thereafter, but with caution due to the often changing profile of the presentation and risks. The young person's risk may reduce significantly with appropriate treatments and new information about diagnosis and need may come to light in the process of assessment and treatment (e.g. a patient presenting with an early onset psychosis, may on remission of these symptoms reveal an underlying developmental disorder that is a predisposing factor and also needs assessment). 
7.2.2. All the diagnostic and potentially de-stabilising factors should be identified in order to inform future care plans, an appropriate placement and assist with prognosis.

7.2.3. Appropriate assessment and fully informed care plans for step-down or return to the community are required to reduce the chance of relapse and future admission, which are often distressing and disruptive to the life of a young person.

7.2.4. Discharge planning should involve the MDT and community services, usually at CPA (or similar) meetings.

7.2.5. Discharge plans should include anticipated time frames and clear goals.

7.2.6. Identified needs should be clearly communicated to external professionals to allow the identification of appropriate step-down and contingency planning.

7.2.7. Once the external professionals involved and responsible for care outside the CAMHS PICU are identified, they should receive regular updates on the young person's progress to allow for prioritisation of the young person and the development and execution of a timely and comprehensive discharge plan.

7.2.8. There are occasions when, due to the severity of their illness, a young person may require a more restrictive environment for the treatment of their illness or an increase in their risk (i.e. step-up). In this case, early discussions with the commissioning team about the appropriateness of the CAMHS PICU environment, and recommendations for alternative appropriate placement, must be made to ensure the safety of the young person and the unit, and to reduce time spent awaiting assessments and transfer.

7.2.9. The clinical team should engage with family and/or carers throughout the admission to increase the likelihood of a safe and successful return to the community.

7.2.10. The clinical team should liaise with the young person's home school or other educational placement to ensure a successful transition back to education.

7.2.11. Nationally, CAMHS PICUs are often located a considerable geographical distance from the young person's home. Therefore units should ensure that a high standard of documentation is shared with the involved community mental health team, members of which may not be able to visit the unit as often as is desirable due to the distance. 
7.2.12. The following steps should be taken to ensure timely discharge:

- Early identification of the receiving community team including the care coordinator and any other professionals involved including social care and education

- Step-down or step-up requirements should be identified as soon as possible to allow time for assessments to take place

- When appropriate, step-down placements should be considered in CPA (or similar) meetings when all the necessary professionals are present; several options could be considered with variations in prognosis and progress in mind

- Throughout the admission, the views of the young person and their family and/or carers must be sought regarding discharge options as appropriate. Looked After Children, or those under Child Protection, the views of the appointed professional should be sought.

- The appropriateness of community placements or the home environment should be tested with appropriate amounts of leave, to allow a smooth transition to the community and avoid the risk of relapse and re-admission, which can often be perceived as a failure by a vulnerable young person. It is good practice, if several periods of leave to a new placement are necessary, for the young person to meet the receiving team, so that they are familiar with the professionals who will be taking over their care and start to develop relationships.

- Recommendations for continuing treatment and relapse prevention work should be communicated to the receiving team in writing if they are unable to attend the final CPA (or similar) meeting prior to discharge

- Receiving teams should be reminded of the constraints of the CAMHS PICU environment and the need to practice least restrictively when it comes to detention of the young person under the MHA 1983 should delayed transfers of care occur

- Multiple short-term moves should be avoided when awaiting a longer term placement, as this may be a de-stabilising influence in the early stages of recovery and remove supportive relationships that a young person may have formed during an admission

- The young person and their family and/or carers, and the agencies involved (including school or other educational placement), should work together to consider the individual needs of the young person, and their de-stabilising and diagnostic factors, to ensure a successful step-down from intensive care. 


\section{Transition \& discharge}

7.2.13. Planning for young people leaving inpatient psychiatric care can be difficult if there is a lack of appropriate resources and placements to meet their needs as they move on. The aim of the CAMHS PICU care pathway should be to plan for step-down or discharge from the point of admission. Any delays due to a lack of appropriate stepdown and transition planning could prove counter-therapeutic as the window of stabilisation and reduction of risk may be lost. It is important to remember that the placement provider may carry out their own assessments. Expectations should not be raised in advance of a move, in case the provider finds that they cannot meet the patient's needs, resulting in disappointment and frustration for the young person.

7.2.14. The following steps should be taken to reduce delays and prevent a revolving door admission cycle:

- Early identification of diagnostic factors and needs involving input from the full CAMHS PICU MDT

- Regular progress reports, including prognostic factors if available, should be given to the external agencies involved during the treatment phase

- Appropriate treatment and interventions should be offered, and effectiveness and progress regularly reviewed

- Problems identifying suitable external professionals should be communicated to the commissioning team early in the admission to avoid unnecessary delays and allow the situation to be rectified.

\section{Delayed transfer of care}

7.2.15. Delayed transfer of care often occurs in complex cases where specialist placements are required and funding needs to be agreed by multiagency panels, or occasionally where local tier 3 or 4 resources are unavailable. If the young person is a Looked After Child whose placement has broken down, it may be difficult to identify a receiving team if the relevant geographical area is unclear. The need to identify specific social care or specialist services should be balanced against the risks of prolonged detention in hospital.

7.2.16. The early identification of placement need, and communication with relevant external agencies, is essential to avoid young people being prematurely discharged by a mental health tribunal without an appropriate placement. The criteria for detention under the MHA 1983 do not take into consideration social care issues, so a mental health tribunal may choose to discharge from section a young person whom they 
deem no longer meets the criteria for detention, regardless of their social circumstances. This could result in premature discharge, where adequate contingency planning has not occurred, all risks have not been considered and tested, and an appropriate environment has not been secured. In this case the young person is at risk of rapid deterioration and re-admission, possibly for a longer period.

\subsection{Good practice guidance}

7.3.1. Good communication with relevant external agencies regarding future discharge is essential at all stages of admission, to include:

- Early identification of the receiving team

- Prognostic factors

- Finding solutions to funding issues

- Ensuring continuation, monitoring and re-assessment of interventions started in the CAMHS PICU.

7.3.2. Early assessment of the young person's future needs is required, including:

- Accommodation

- Education

- Training and employment

- Social life and relationships

- Support from family and friends

- Risks and triggers for relapse and re-admission to the CAMHS PICU. 


\section{Physical environment}

\subsection{Rationale}

The physical environment should reinforce the primary function of a CAMHS PICU, which is to maximise safety, and allow adequate engagement in therapy. The building design should be at least as robust as that of an adult PICU (NAPICU, 2014) and allow for protection against aggressive, impulsive and unpredictable incidents, self-harm or suicidal behaviours, and absconding. There should be a balance between space for therapeutic activities, and a homely environment where young people spend the majority of their day.

\subsection{Standard}

8.2.1. The physical environment of the CAMHS PICU should be designed with the needs and potential expectations of young people in mind.

8.2.2. The CAMHS PICU should be separate from any adult PICU on the same site.

8.2.3. If facilities are shared with an adult PICU, policies should be in place to ensure that young people do not use them at the same time as adults.

8.2.4. The design should follow the service standards recommended by QNIC (Thompson \& Clarke, 2013; Clarke \& Thompson, in press).

8.2.5. An annual environmental risk assessment should be carried out, and appropriate risk management strategy agreed.

\section{Location}

8.2.6. The CAMHS PICU should not be isolated but should be part of a psychiatric campus to enable emergency response from other units (see Chapter 5).

8.2.7. The CAMHS PICU should be located on the ground floor.

\section{Entrance}

8.2.8. If the CAMHS PICU is part of a hospital, the entrance should be external so as to obviate the need to access it through the rest of the hospital.

8.2.9. The main entrance should be located away from the main clinical area.

8.2.10. The entrance should have wheel-chair access.

8.2.11. The entrance to the CAMHS PICU should not be via the patient day space; alternative entrances to parts of the PICU should be integrated into the design. 
8.2.12. There should be the means, in an emergency, to allow quick access to the building with minimal compromise of security procedures.

\section{PICU area, bedrooms \& corridors}

8.2.13. The CAMHS PICU should aim to provide a homely, calming environment with careful attention to aspects such as colours, artwork and soft furnishings. It should be a low sensory stimuli environment. This should apply to the whole unit (i.e. no strident colours, bright lights or loud noises).

8.2.14. Specific attention should be paid to aspects of the environment that affect the acoustics, with the aim of keeping noise travel to a minimum (e.g. by reviewing ceiling height and materials, soft furnishings, floor coverings or carpets etc.).

8.2.15. In mixed sex CAMHS PICUs, gender specific areas such as bedrooms, corridors and toilets should be provided as outlined in the QNIC service standards (Thompson \& Clarke, 2013; Clarke \& Thompson, in press).

8.2.16. The number of beds should not exceed ten.

8.2.17. Corridors should provide for unobtrusive observation.

8.2.18. Corridors should allow for at least three individuals to walk comfortably abreast.

8.2.19. All areas, where possible, should have a clear line of sight, with use of aligned windows or convex mirrors. Multiple corridors should be avoided.

8.2.20. The CAMHS PICU must be robust with a design based on a risk assessment of the environment (e.g. pipes and wires should be hidden and inaccessible to patients).

8.2.21. Technology should be used to minimise ligature points (e.g. sensor taps).

8.2.22. A comfortable temperature should be maintained within the CAMHS PICU, with local controls for staff to regulate heating and ventilation.

8.2.23. Young people should be able to control light, water and ventilation in their bedrooms, but staff should be able to over-ride these when necessary (e.g. dimmer type light switches in bedrooms, controlled from both inside and outside to allow for night time observation).

8.2.24. Bedrooms should include a lockable cupboard for possessions, but it should be remembered that large amounts of storage space can make room searches lengthy.

8.2.25. There should be an area designated for family visiting, which is child friendly and suitable for young siblings. 
8.2.26. Where clinically appropriate, facilities should exist for families to stay overnight within the hospital campus.

8.2.27. There should be access to private areas for young people to use the telephone for family contact, legal consultation and so forth, and this should be out of hearing of the other patients in a designated area.

\section{Fire entrance/exits}

8.2.28. Fire procedures should be compliant with the law.

8.2.29. All fire entrances and exits should be clearly marked with easy access.

\section{Windows}

8.2.30. The design should allow for maximum daylight into the CAMHS PICU (e.g. skylights in main corridors).

8.2.31. Windows should be plexi-glass or equivalent to prevent breakage.

8.2.32. Windows should allow opening of up to $125 \mathrm{~mm}$ to allow for ventilation.

8.2.33. Fittings should be risk assessed to avoid any ligature points.

\section{Doors \& locks}

8.2.34. All doors should be of solid construction of at least $40 \mathrm{~mm}$ thickness.

8.2.35. The doors should open outwards to reduce the risk of barricading.

8.2.36. All doors, with the exception of toilets and bathrooms should be provided with a polycarbonate observation panel, to enhance safety.

8.2.37. Transitions from spaces should be easy in difficult situations. For example, rooms such as the day room, dining room and activities hall should have double doors which remain open for free access of patients the majority of the time.

8.2.38. The kitchen area should be controlled and the design should include the facility to prevent access by young people if not authorised.

8.2.39. Bedrooms, bathrooms and toilets should be lockable from the inside, and staff should be able to over-ride these locks from the outside in an emergency. Consideration should be given to electronic access control with the facility to allocate fobs to patients with specific risk assessed access authorities.

8.2.40. Bathrooms and toilets should be fitted with fish-eye observation lenses to observe high risk patients.

8.2.41. All doors should close quietly to avoid unnecessary noise. 


\section{Furniture}

8.2.42. The CAMHS PICU environment should be as comfortable as possible.

8.2.43. The furniture should be designed to reduce the risk of hiding weapons and should also be of a weight which reduces the risk of throwing the furniture.

8.2.44. Floor surfaces should be robust and clean.

8.2.45. The design and fittings of the CAMHS PICU should minimise sound and be acoustically effective.

\section{Therapy \& recreation facilities}

8.2.46. There should be access to an enclosed garden, the fences around which should be of a sufficient height to avoid climbing or access to the roof.

8.2.47. Young people should have access to an outdoor space for 30 minutes a day (dependent on weather and clinical condition).

8.2.48. There should be multipurpose rooms with easy access for use for quiet time, deescalation, one-to-one sessions etc.

8.2.49. There should be a space where daily living skills can be assessed, maintained or developed (e.g. an adapted kitchen). This would require risk assessment.

8.2.50. Young people should have access to a quiet room in addition to any seclusion facilities.

8.2.51. There should be an activities room with access to age appropriate entertainment.

8.2.52. There should be a day room and sitting room with television and DVD player. This should be contained in a secure cabinet where possible, or mounted out of reach to avoid damage or hiding of items.

8.2.53. There should be a multi-faith room where young people can make religious observance according to their own beliefs.

8.2.54. Use of laptops and mobile phones and similar devices should be considered where possible, with supervision, according to individual risk assessments.

8.2.55. There should be a room with equipment to encourage physical fitness. Equipment should be secured to the floor; loose equipment is not advisable. 


\section{Education}

8.2.56. Suitable facilities should be provided for education, this should include a designated classroom space which can accommodate all students (see Chapter 16).

8.2.57. The classroom should include one computer for every two students.

8.2.58. Education should be offered on the CAMHS PICU if the young person is unable to attend the classroom.

\section{Sensory room}

8.2.59. A sensory room should be provided within the CAMHS PICU as a space for reducing arousal levels of young people.

\section{Extra care areas \& seclusion facilities}

8.2.60. An extra care area (ECA) within the CAMHS PICU can provide a quiet, low-stimulus space for young people experiencing high levels of arousal during periods of disturbed behaviour and can be used for de-escalation, patient support and management, and treatment in a bespoke space for high intensity intervention.

8.2.61. Any ECA should provide for the daily living needs of a single patient for a limited period. It should include:

- De-escalation and/or seclusion room

- Toilet and shower facilities

- Sitting room with safe furnishings (i.e. robust, recommended furniture, or lightweight furniture which would not cause injury if thrown).

8.2.62. Use of an ECA must be compliant with the requirements of the MHA 1983 Code of Practice (Department of Health, 2015, para. 26.35) which states that 'If an individual under long-term enhanced observation is also being prevented from having contact with anyone outside the area in which they are confined, then this will amount to either seclusion or long-term segregation which should comply with paragraphs 26.103-26.160.'

8.2.63. The ECA and any seclusion facility should be located in an area away from the main patient areas and bedrooms.

8.2.64. It should be possible to regulate both room temperature and ventilation in the ECA and in any seclusion facility.

8.2.65. The ECA should offer privacy from other patients, visitors and, when clinically appropriate, from staff with a maintained ability to observe. 
8.2.66. The ECA and any seclusion facility should be robust enough to withstand determined attack.

8.2.67. The ECA should not be included in the bed numbers for the unit.

8.2.68. Where a seclusion facility is available for use, there should be a designated facility which:

- Allows clear observation, but also privacy for the young person

- Does not have a door leading directly into the day space and ideally is away from communal areas to reduce noise disturbance

- Is well insulated and ventilated

- Has direct access to toilet and washing facilities

- Is safe and secure, and does not contain anything which could cause harm to the young person or others

- Includes a means of communicating with staff.

\section{Staff \& patient safety}

8.2.69. Young people should have a means of raising an alarm in an emergency.

8.2.70. Personal alarm systems should be carried by staff, which when activated should alert colleagues to an emergency and its location.

\section{Communication systems}

8.2.71. During escorted leave, staff members should use a two way radio system or any other established means of communication.

\subsection{Good practice guidance}

8.3.1. To create a physical environment with the key requirements of safety, a place to engage in therapeutic activities, and a homely atmosphere, refer to the following guidance:

- QNIC Service Standards (Thompson \& Clarke, 2013; Clarke \& Thompson, in press)

- National Minimum Standards for Psychiatric Intensive Care in General Adult Services (NAPICU, 2014)

- Safety, Privacy and Dignity in Mental Health Units (NHS Executive, 2000)

8.3.2. In area such as corridors, ceiling height should be at least $3 \mathrm{~m}$ to create a feeling of space. 


\section{Safeguarding}

\subsection{Rationale}

The statutory requirements for safeguarding are outlined in the Children Act 1989, 2004. NHS organisations and those providing services on its behalf are required to ensure that 'their functions are discharged having regard to the need to safeguard and promote the welfare of children' (Children Act 2004, Section 11).

Every Child Matters (HM Treasury, 2003) outlined five outcome areas which aimed not only to protect but to ensure the best possible quality of life for children and young people:

- Being healthy

- Staying safe

- Enjoying and achieving

- Making a positive contribution

- Economic well-being.

CAMHS PICUs will be part of a system working in partnership with local mental health, education and social care services to ensure that safeguarding concerns are identified and appropriately managed.

\subsection{Standard}

9.2.1. The CAMHS PICU's safeguarding policies and procedures should:

- Ensure that safeguarding is a core responsibility for all staff

- Refer appropriately to the local safeguarding children boards (and their policies and procedures) for the relevant home area of each young person, and for the area in which the provider is operating

- Provide clear advice on information sharing

- Provide clear guidance on prompt reporting of safeguarding concerns

- Require monitoring of all episodes of control and restraint, and seclusion.

9.2.2. The CAMHS PICU should have an identified safeguarding lead.

9.2.3. All staff are subject to an enhanced disclosure and barring service check prior to commencing employment.

9.2.4. All clinical staff should receive Level 3 safeguarding training. 
9.2.5. All other staff should receive Level 1 safeguarding training.

9.2.6. There should be a policy and procedure for the prevention and management of bullying.

\subsection{Good practice guidance}

9.3.1. The CAMHS PICU should be able to demonstrate a positive culture of safeguarding which actively shares information and encourages openness both between individuals and organisations.

9.3.2. The CAMHS PICU should develop initiatives which role model and promote positive and mutually beneficial relationships. 


\section{Legal frameworks \& practice}

\subsection{Rationale}

Because of the secure and involuntary nature of most CAMHS PICU admissions, the legal status of the young person, as well as those who are legally entitled to make decisions about their care, should be carefully considered and understood. The MHA 1983 applies in CAMHS PICU environments in the same way as it applies in any other inpatient hospital setting.

\subsection{Standard}

The following standard should be read in conjunction with the information and definitions provided in Appendix 2.

10.2.1. Each CAMHS PICU should have operational procedures and frameworks in place to ensure adherence to the MHA 1983 Code of Practice (Department of Health, 2015).

\section{Parental responsibility}

10.2.2. If it is not immediately clear, all parties with parental responsibility (see Appendix 2) should be identified on admission. Where more than one person has parental responsibility, each of them may act alone and without the other (Children Act 1989, Section 2(7)) but where there are disagreements, it is advisable to seek the advice of the court where feasible (Department of Health, 2015).

10.2.3. Under the Mental Capacity Act 2005, any capacitated decision made by a young person aged 16 or above cannot be overridden by someone with parental responsibility, except in extreme circumstances (i.e. serious injury or death). The MDT should always seek a competent or capable young person's consent before providing treatment unless any delay involved in doing so would put the young person's life or health at risk.

10.2.4. Children under the age of 16 should be as involved as possible in decisions about their healthcare (see also 10.2.21).

10.2.5. Any differences of opinion between the young person and their parents, or between parents, should be clearly documented in the young person's notes. 


\section{Assessing capacity or competence}

10.2.6. It may be difficult and complex to assess capacity or competence, as it varies according to time, issue and the specific clinician who may be assessing it. The understanding required to consent to different interventions may vary considerably, and a young person may have capacity to consent to some interventions but not others. Capacity to consent should therefore be assessed for each decision.

10.2.7. As mental disorder can cause significant fluctuations in mental state over time, capacity should be considered at the time the young person needs to make a decision.

10.2.8. When assessing whether a young person is able to consent, follow the Mental Capacity Act 2005 (paras 13.17-13.22) which applies to people aged 16 or over, and indicates that young people must be assumed to have capacity to make a decision about a proposed admission to hospital and/or treatment unless it is established that they lack capacity, as is the case with adults (Department of Health, 2015, para. 19.26). Those under 16, should be assumed to lack competence until proven otherwise.

10.2.9. The Mental Capacity Act 2005 sets out a two-stage test for lack of capacity for those aged 16 years and above:

- There must be an impairment of, or disturbance in the functioning of, mind or brain

- This impairment or disturbance means that the person is unable to make a specific decision when they need to.

10.2.10. To give informed consent a person must be able to:

- Understand the information about the decision to be made

- Retain the information in their mind

- Weigh up this information in order to make the decision

- Communicate their decision in some way.

10.2.11. A record should be kept of the information provided. Just because a person can only retain information for a short period does not necessarily mean that they are unable to make a decision (Mental Capacity Act 2005, Section 3; Department for Constitutional Affairs, 2007, para. 4.14). If being treated under the Mental Capacity Act 2005, restraint can only be used if it is believed to be necessary to prevent harm 
to the person who lacks capacity, and is a proportionate response to the risk of serious harm.

10.2.12. The young person should be provided with easily understandable, age-appropriate information.

10.2.13. In decision-making with or about young people, specific issues should be considered (Department of Health, 2015):

- The best interests of the young person

- The views of the young person

- Use of the least restrictive option (bearing in mind the risks posed); clinicians must avoid stigmatisation, aim for the least degree of separation from family, friends and the local community, and wherever possible avoid disruption to education

- The right of the young person to dignity and respect

- The right of the young person to privacy and confidentiality.

\section{The scope of parental responsibility}

10.2.14. The scope of parental responsibility covers those decisions which would reasonably fall under the remit of a parent or person with parental responsibility, i.e. decisions which a parent would reasonably be expected to make. The boundaries of this scope are not fixed, and its size will vary. There may be circumstances in which a parent might not act in the best interests of their child (e.g. during an acrimonious divorce where the young person is caught between two parents who are not making the young person's needs paramount, or where the young person alleges abuse from a parent and the same parent supports certain forms of psychiatric treatment). If the MDT does not feel sure that the person with parental responsibility is acting in the best interests of the young person, it is more likely that a decision regarding treatment will fall outside the scope, and parental responsibility should not be relied upon.

10.2.15. In terms of admission, the majority of young people will be detained under the MHA 1983. It is no longer legal to use parental responsibility powers to admit a 16 or 17 year old to hospital against their will if they have the capacity to refuse this admission. Similarly if a competent child under the age of 16 refuses hospital admission, parental consent should not be relied upon. 
10.2.16. The CAMHS PICU should not rely on parental consent to authorise admission or treatment for any patient (irrespective of age, capacity or competence status). This reflects the secure nature of the environment and the use of measures such as prevention and management of aggression and violence, intramuscular medication and, on occasion, seclusion facilities and extra care areas. For these reasons it is advised that the MHA 1983, which carries with it due process, automatic appeal mechanisms and other safeguards, should be the preferred method of detention.

10.2.17. When a young person reaches the end of their treatment phase and is acquiring greater degrees of independence, it may be feasible for them to achieve an informal status. This may occur via tribunal or manager's hearing discharge from the MHA 1983, or the treating responsible clinician may discharge the Section.

10.2.18. Each CAMHS PICU should provide an informal patient policy document which describes the mechanisms by which these young people can be managed, for instance conditions of leave, safeguards if a mental health deterioration occurs and so forth.

10.2.19. Children under the age of 16 who understand fully what is involved in a proposed procedure can give consent where they are considered competent to do so (although their parents should ideally be involved).

10.2.20. If a young person is considered to lack competence or capacity, someone with parental responsibility must give consent on the young person's behalf, unless they cannot be reached in an emergency.

10.2.21. A parent can consent to treatment if a competent child under the age of 16 refuses such treatment, as long as the decision falls within the scope of parental responsibility (see also 10.2.3).

10.2.22. There are circumstances under which no parent could be expected to make a decision, for instance ECT, or psychosurgery. The need for nasogastric feeding for conditions such as anorexia nervosa may arise in young people's mental health services and each case must be judged on its merits.

\section{Deprivation of liberty}

10.2.23. Article 5 of the European Convention on Human Rights - the right to liberty - applies to people of all ages, including young people under the age of 18. It is therefore important to determine whether the admission to hospital and the assessment and/or treatment in hospital amounts to a deprivation of liberty. 
10.2.24. This must be determined on a case by case basis. The MHA 1983 Code of Practice provides guidance in this area (Department of Health, 2015).

10.2.25. Authority for a deprivation of liberty can come from the MHA 1983, or the Court (Court of Protection for over 16s).

10.2.26. Case law had previously determined that a person with parental responsibility could not authorise a deprivation of liberty (RK v BC et al. 2011). The MHA 1983 Code of Practice states that while the more recent and very significant case of Cheshire West (P v Cheshire West \& Chester Council 2014) clarified the elements establishing a deprivation of liberty, it did not expressly decide whether a person with parental responsibility could, and if so in what circumstances, consent to restrictions that would, without their consent, amount to a deprivation of liberty (Department of Health, 2015). A subsequent case held that this could in fact be so ( $\operatorname{Re} D, 2015)$. This is clearly a complex and developing area of law.

10.2.27. Legal advice should be sought for individual cases as necessary.

\section{Electroconvulsive therapy (ECT)}

10.2.28. No patient under 18 can be given ECT without the certification of a second opinion appointed doctor (SOAD), whether detained under the MHA 1983 or not. Consent (or some other legal authority) must also be obtained if the patient is voluntary. This treatment is highly likely to fall outside the scope of parental responsibility due to its invasive and controversial nature.

\section{Research}

10.2.29. There is a presumption of a lack of capacity for 16 and 17 year olds in relation to research. This differs from the usual presumption that 16 and 17 year olds have capacity until proven otherwise and is present in order to ensure that young people have appropriate safeguards for particularly serious decisions.

\subsection{Good practice guidance}

10.3.1. Practitioners should be familiar with relevant legal frameworks and terminology (see Appendix 2).

10.3.2. Further guidance is provided by the Department of Health (2001a, 2008). 


\section{Multidisciplinary team workforce \& staffing}

\subsection{Rationale}

Psychiatric intensive care is an integral component of the young person's acute inpatient psychiatric care pathway, caring for the most acutely unwell and disturbed children and adolescents in psychiatric services. Such young people require intensive assessment and treatment during this phase of their illness; this should be delivered in a specialised environment by a team of highly skilled staff who have regard for the needs of the young people, and their family and/or carers, with whom they work.

The team should be skilled in the assessment and management of the mental and physical health disorders presented by young people within acute inpatient psychiatry. The CAMHS PICU MDT, its make-up and functioning, are crucial factors in the provision of a safe, effective and quality service.

Staffing should be sufficient to safely deliver optimal treatment and care, manage demand, and be responsive to critical care, 24 hours a day, 7 days a week.

\subsection{Standard}

\section{Multidisciplinary team (MDT)}

11.2.1. There should be a comprehensive, cohesive and effective multidisciplinary approach to delivering care to the young people.

11.2.2. The strength of the CAMHS PICU team in delivering high quality patient care is in its full multidisciplinary nature. The MDT should include a broad range of professionals, over and above the core nursing and medical professionals.

11.2.3. Contributions from all members and all levels of the MDT should be valued and carefully appraised.

11.2.4. Staff should have the capacity and capability to engage effectively with highly disturbed young people with complex needs, to provide a range of multidisciplinary therapeutic interventions and clinical treatments. 
11.2.5. All CAMHS PICUs should have input from professionals in the following disciplines within the context of core team skills:

- Medical (a consultant psychiatrist and a junior psychiatric doctor)

- Nursing (a team of specialist inpatient nurses, including registered nurses, healthcare support workers and assistant practitioners)

- Education (minimum of one qualified teacher and one member of support staff to four students; see Chapter 16)

- Management (a ward/unit manager and a deputy with relevant clinical expertise)

- Occupational therapy (an occupational therapist with specialist skills in acute psychiatric inpatient care and support staff (e.g. activities co-ordinator) who can provide a defined activity programme available to all patients including evenings and weekends)

- Pharmacy (a specialist pharmacist with experience in acute inpatient settings)

- Psychology (clinical psychologists and other staff skilled in delivering psychological interventions)

- Social work (access to a social worker to address holistic care needs)

- Activity, physical health and engagement (e.g. physiotherapist, sports therapist, dietician).

11.2.6. It is recommended that young people have access to the following staff (this list is not exhaustive):

- Phlebotomists

- ECG technicians

- Dieticians

- Physiotherapists

- Peer support workers

- Other therapy staff (e.g. art therapists, music therapists)

- Sports/exercise therapists

- Advocates

- Chaplains

- Interpreters (as well as sign language and other communication media as appropriate). 
11.2.7. If staff from any of these disciplines are not directly provided for within the CAMHS PICU team, there should be local contractual arrangements in place to provide these in a sustained fashion (e.g. service level agreements with the local acute medical hospital for pharmacy services, contracts for psychologist input, occupational therapy input and sessional therapy staff).

\section{Staffing levels: general principles}

11.2.8. The provision and delivery of an effective CAMHS PICU service requires sufficient and specialist support from both established staffing levels and affiliated clinical and managerial resources.

11.2.9. At all times the available staff should be sufficient in number and competency to safely treat and manage the patients.

11.2.10. The unit should have an agreed core establishment, providing a minimum staffing level across all hours.

11.2.11. There should be managerial systems in place to ensure that all factors affecting staffing numbers and skill mix are considered.

11.2.12. Staff levels should be reviewed on a daily basis.

11.2.13. The names of staff working on the shift should be displayed for all patients to see.

11.2.14. The factors that affect staffing levels are:

- Therapeutic engagement

- Clinical interventions such as need for higher observation levels

- Staff capabilities (i.e. skill mix)

- Training

- Tertiary factors such as sickness, training, leave and capacity which may be lost due to organisational responsibilities

- Supervision

- Staff needed to escort young people going on leave

- Acuity levels

- Number of active (usable) beds within the CAMHS PICU

- Bed occupancy.

11.2.15. It is important that there is agreement between front line clinical leadership and senior operational managers regarding safe minimum staffing levels to ensure quality of patient experience. 
11.2.16. CAMHS PICUs require proportionally higher staffing levels than would ordinarily be available in the general acute CAMHS ward.

\section{Nursing staff}

11.2.17. The nursing establishment for each unit should be developed by registered nurses practising at the front line in conjunction with senior managers, and should be approved by the chief nurse with the provider operational organisation's board retaining responsibility (NICE, 2014).

11.2.18. A nursing team consists of registered specialist mental health nurses, plus unregistered nursing staff such as healthcare support workers and assistant practitioners.

11.2.19. Staff posts required on a CAMHS PICU will vary according to a number of factors but will predominantly be based on the number of beds and bed occupancy. It should take into account planned and predictable variations in staff availability (e.g. due to all types of leave) (NICE, 2014).

11.2.20. The NICE (2014) guidance for staffing levels in acute hospital adult inpatient wards does not specify nursing staff-to-patient figures for minimum safe care, but emphasises the need for local decisions that reflect the requirements of the patient group. Thus, higher staffing levels are required on medical intensive care wards as compared to general medical wards (in general medical hospitals). The same principle should to be applied to psychiatric wards: higher staffing levels are required on PICUs as compared to general psychiatric wards.

11.2.21. Nursing staffing levels in the CAMHS PICU should not depend solely on the core establishment; staff mix and ratios should be flexible enough to meet changing levels of clinical and risk need, the above factors should be taken into consideration.

11.2.22. The following are recommended based on clinical and operational experience:

- The nursing staff establishment on a CAMHS PICU should be at least one third higher than on general acute psychiatric wards (weighted per bed)

- A third of the nursing staff should be registered on each shift, with no fewer than two per shift

- As an example, the number of staff per shift for ten patients in a CAMHS PICU should not fall below six for the early and late shifts, and four for the night shift. These numbers should not include management and specific therapy staff. 


\section{Medical staff}

11.2.23. Each CAMHS PICU should have dedicated consultant psychiatrist able to function as the responsible clinician within the meaning of the MHA 1983; plus at least one single dedicated lower grade doctor (often a trainee psychiatrist).

11.2.24. Medical staffing levels need to be determined locally based on a variety of factors, including the clinical characteristics of the patients, the size of the CAMHS PICU, the acuity levels, the strength of CAMHS PICU interfaces with acute wards and other services, and any associated responsibilities of the CAMHS PICU consultant psychiatrist (in terms of other clinical roles, training, management and leadership).

11.2.25. A doctor should be available at all times (both within routine 'office hours' and outof-hours) to be alerted to both medical and psychiatric emergencies, and urgent or critical scenarios on the CAMHS PICU. This doctor should be able to attend the CAMHS PICU in a timeframe appropriate to respond to clinical emergencies.

\section{Other staff}

11.2.26. The CAMHS PICU should have a qualified specialist clinical psychologist for a minimum of one day per week, to deliver face-to-face patient care, such as psychotherapy and family therapy.

11.2.27. There should be a specialist mental health pharmacist to visit the CAMHS PICU on a daily basis, take part in the weekly multidisciplinary reviews; and have associated support staff (e.g. pharmacy technicians/assistants).

11.2.28. The CAMHS PICU should have access to the following educational staff (see also Chapter 16):

- A minimum of one qualified teacher and one member of support staff to four students per lesson

- Specialist teachers as required (e.g. language tutors)

- Other educational professionals (e.g. careers advisor, educational psychologist).

11.2.29. Teachers should regularly attend and contribute to MDT meetings.

11.2.30. Student placements of all disciplines play an important role as students make a positive contribution to the care and treatment of patients, but students should be considered supernumerary. 


\section{Leadership}

11.2.31. The CAMHS PICU ward manager should be a senior registered nurse with significant inpatient experience and expertise. They have a key role in clinical leadership and should take an equal share of this in partnership with the dedicated lead consultant; they should have suitable skills to do so. They should have appropriate authority to lead the CAMHS PICU and make decisions regarding all aspects of unit operation. For many operational issues, this requires the support of senior management within the mental health organisation overseeing the CAMHS PICU.

11.2.32. The CAMHS PICU ward manager should have a particular focus on the overall team performance, ensuring the safe care of the patients, the quality of clinical approaches, and safety of the staff.

11.2.33. The CAMHS PICU lead consultant should provide expert input into the clinical, managerial and operational matters relating to the CAMHS PICU service.

11.2.34. The dedicated lead consultant should have specific sessions or time-slots set out in the consultant job-plan to ensure consistent managerial and leadership input to the CAMHS PICU and the wider forums that are associated with the CAMHS PICU and its interfaces.

11.2.35. Other specialist professionals within the CAMHS PICU team (e.g. psychologist, occupational therapist and pharmacist) should also exercise leadership in maintaining the quality, diversity and safety of the clinical approaches used within the unit.

\subsection{Good practice guidance}

11.3.1. Consideration needs to be given to appropriate role definition concerning members of the MDT fulfilling interventions provided by the CAMHS PICU. This improves team functioning and thus provision of care.

11.3.2. The CAMHS PICU team should consider innovations in staffing, staff roles and responsibilities; for example there may be a role for a consultant nurse, the use of Patient Group Directions, and non-medical prescribers.

11.3.3. There is no set standard for the number of CAMHS PICU beds to be provided per head of population in the UK. Commissioners should use the principles outlined in this document to locally devise the level of CAMHS PICU bed provision required. 
This will vary regionally depending on local factors. As with all clinical services, the balance between local assessment of need and the commissioned provision should be reviewed frequently from the organisational perspective, at least every three years.

11.3.4. From a clinical and operational perspective smaller PICUs tend to function better. No more than 10 beds are recommended (see Chapter 8). Commissioners and managers should be aware that there is not a direct linear relationship between staffing numbers (e.g. a 5-bed PICU does not require half the staffing of a 10-bed PICU).

11.3.5. There is a continued lack of UK-wide leadership in CAMHS nursing (Royal College of Nursing, 2014). It is the responsibility of every nurse working with young people to promote and inform policy, whether locally or more widely. 


\section{Staff supervision, training \& continuing professional development}

\subsection{Rationale}

The CAMHS PICU should be a dynamic clinical and learning environment committed to training and development. Supervision is part of this commitment. Staff supervision is widely accepted as an essential prerequisite for high quality care and is a regulatory requirement in the UK for healthcare professionals.

In the highly demanding and potentially stressful work environment of a CAMHS PICU, it is essential that staff are well-trained. In a ward with a culture of using evidence-based practice, it is important that clinicians are up to date with their knowledge and skills pertaining to their specialist area in order to provide high quality care.

Continuing professional development (CPD) should meet the needs of patients, help organisations to deliver their objectives for improving healthcare, as well as assist individuals to expand and fulfil their potential. Effective CPD relies on shared understanding between units, staff, regulatory bodies, and learning providers.

\subsection{Standard}

\section{Supervision}

12.2.1. All clinical staff (not just nursing) and students should have supervision at a minimum of once every four weeks or more frequently as per professional body guidance (e.g. Royal College of Nursing, 2014).

12.2.2. Non-regulated health and social care support workers should receive supervision from a registered practitioner.

12.2.3. The supervision process should be explained to any new member of staff during induction.

12.2.4. The requirement to participate in supervision should be included in the job description for every member of the team.

12.2.5. Teams should have robust systems of clinical supervision in addition to managerial supervision.

12.2.6. Supervision should be recorded. Each unit should have a well-defined and robust system of monitoring and auditing supervision. 
12.2.7. All CAMHS PICUs should have clear clinical supervision guidelines which incorporate supervision contracts between supervisor and supervisee to cover:

- Learning/training objectives

- Resolution of conflict (arbitrator identified)

- Roles and responsibilities

- Practicalities (e.g. location)

- Boundaries (e.g. time and agreed agenda)

- Documentation to be used

- Confidentiality (adherence to professional code of conduct and organisational policy)

- Actions in event of non-attendance or cancellation

- Frequency and duration.

12.2.8. Emergency ad hoc supervision and other support measures should be available in times of crisis and following untoward incidents.

12.2.9. Where managerial and clinical supervision is combined, supervision should adhere to a specific structure (relevant to the appropriate professional body) and also address both clinical and managerial factors including:

- Monitoring (including patients' concerns)

- Caseload supervision

- Development (core skills \& training for staff)

- Self-development

- Support in stressful situations

- Action plans (shared agreement of actions)

- Safeguarding.

12.2.10. All staff should have an annual appraisal.

12.2.11. Reflective practice should occur regularly and be open to all members of the MDT. Additional sessions should be provided following serious incidents. These strengthen communication and working relationships, and promote learning which in turn contributes to increased effectiveness in risk assessment and management. 


\section{Training for all staff}

12.2.12. There should be an organisation-wide strategy in place to ensure that training is available. There should be organisation-wide mandatory training to meet legislative requirements. Additionally there should be a specific training programme to cater for the clinical skills necessary for those working with children and adolescents, and in psychiatric intensive care. This should then be tailored to the local MDT.

12.2.13. The following core competencies should form the basis of a training and development plan:

- Ethical practice

- Knowledge

- Process of care

- Interventions

- Applications to the CAMHS PICU settings

- Equality and cultural capability

- Innovation.

12.2.14. Access to training should be facilitated and there should be arrangements for staff cover to allow others to attend training.

12.2.15. All staff should complete a security induction programme prior to being issued with secure keys, pass cards or fobs and personal alarms, and have a security awareness refresher annually.

12.2.16. All staff should receive suitable guidance and training in order to operate in accordance with the relevant standard operational procedures in place on the CAMHS PICU.

12.2.17. All new staff should be allocated a mentor to oversee their induction.

12.2.18. The CAMHS PICU budget should be sufficient to enable staff to attend the required training.

12.2.19. All staff training should be underpinned by a clear philosophy on the provision of care within this population and the CAMHS PICU setting, and address the specific challenges that working in a CAMHS PICU presents.

12.2.20. The CAMHS PICU should be considered to be a high stress environment and provision should be made for a staff away-day at least annually. 


\section{Training for clinical \& educational staff}

12.2.21. Staff should complete a unit-based induction programme which ensures basic understanding of core skills. Where additional required training is identified, it should be delivered and prioritised according to safety and quality impact, as well as patient need. Each new staff member should be able to demonstrate those competencies appropriate to their job or role within six months of joining the team.

12.2.22. Before being asked to carry out any clinical work, all staff should receive mandatory training in fire safety, manual handling, infection control and basic life support.

12.2.23. All staff should attend identified statutory and mandatory training (including risk assessment and safeguarding) and six other practice-associated days per year.

12.2.24. All staff are responsible for ensuring that they are familiar with, understand and implement the local organisation's key policies in relation to their practice (e.g. nursing observation policy, incident reporting, management of serious incidents, management of misuse of substances, seclusion, absence without leave (AWOL) and safeguarding procedures).

12.2.25. All training relating to patient care should be specifically tailored for this patient population (i.e. young people) and the staff member's profession (Royal College of Nursing, 2014).

12.2.26. All organisations should have a policy for training employees in relation to the shortterm management of disturbed or violent behaviour in young people. This policy should specify who will receive what level of training (based on risk assessment), how often they will be trained, and also outline the age appropriate techniques in which they will be trained (see Chapters 5 \& 15).

12.2.27. All staff based on the unit should be trained in the management of disturbed behaviour in young people. This ongoing competency training should include the skills to recognise anger, potential aggression, antecedents and risk factors of disturbed of violent behaviour and to monitor their own verbal and non-verbal behaviour. Training should include methods of anticipating, de-escalating or coping with disturbed or violent behaviour (NICE, 2015a).

12.2.28. All regular and temporary (bank and agency) nursing staff should be trained and competent in the use of breakaway techniques, conflict resolution, the management of disturbed behaviour and the therapeutic management of violence and aggression 
(TMVA) (including restraint) and observation of young people. Other ward based staff may also be trained (e.g. occupational therapists, doctors, educational staff).

12.2.29. All TMVA education and training should be based on current national guidance and contain significant elements on prevention and de-escalation. It should be tailored for use with young people.

12.2.30. All staff who undertake physical intervention/restraint or seclusion should be trained in basic life support as a minimum (Nolan, 2010).

12.2.31. All staff involved in administering or prescribing RT, or monitoring young people to whom parenteral RT has been administered, should receive ongoing competency training to a minimum of Immediate Life Support (covering: airway, cardio-pulmonary resuscitation (CPR) and use of defibrillators; Nolan, 2010) (see 15.2.39-15.2.41).

12.2.32. CAMHS PICUs should provide a significant proportion of the MDT access to training that equips healthcare professionals with the competencies required to deliver the psychological therapy interventions recommended in these standards in line with national guidance.

12.2.33. Continuing training and refresher courses (e.g. interpersonal skills) should be available to all staff. In particular, non-registered members of the team frequently spend significant periods of time with the young people. These staff should be supported to develop skills in listening, conversation, observation and engagement as well as primary prevention and de-escalation.

12.2.34. Staff who undertake assessment and care planning should have received training in:

- Risk assessment, management and risk-taking

- De-escalation techniques

- Management of violence and aggression

- Rapid tranquillisation (RT)

- Use of restraint techniques

- Assessing mental capacity

- Self-harm and suicide, awareness and prevention techniques

- Care planning, including transfer/discharge planning

- Assessing carers' needs

- Equality and diversity

- Safeguarding children. 
12.2.35. Regular training in addressing inequality issues and developing cultural competence should be available to all staff.

12.2.36. All practitioners who administer medicines should successfully complete a competency assessment; records of this assessment should be available on the unit.

\section{Training for medical staff}

12.2.37. Training should be provided in prescribing medicines specifically for use in this population; this includes specific training regarding the use of 'off-label' medicines, and for the prescription of RT.

12.2.38. All prescribers should undertake an assessment of competency in the prescribing of medicines; records of this assessment should be available on the unit.

12.2.39. Training should be provided in undertaking physical examinations of patients.

12.2.40. In-depth training should be provided in relation to the MHA 1983 with specific emphasis on Part III.

12.2.41. Training for Section 12 approval under the MHA 1983 should be a requirement of all practising consultant psychiatrists within the CAMHS PICU.

\section{Continuing professional development (CPD)}

12.2.42. $\mathrm{CPD}$ is a continuous process of learning. All registered practitioners are required to undertake CPD as a part of registration and revalidation. Non-registered staff should also undertake CPD.

12.2.43. CPD should focus on improving the skills and knowledge of staff so as to ensure that care provision is of a high quality and that admission to the CAMHS PICU is a beneficial experience for patients.

12.2.44. A programme of individual CPD should be detailed in an agreed framework, such as the appraisal process.

12.2.45. Team members should ensure that their CPD has contributed to the quality of their practice and service delivery, and that their CPD benefits the patients. 


\subsection{Good practice guidance}

12.3.1. A relevant evidence-based model for clinical supervision should be identified and implemented within the unit.

12.3.2. Supervision should take place in a comfortable and private room away from the workplace, free from interruption.

12.3.3. Staff should be able to choose their clinical supervisor.

12.3.4. Supervision records of the team should be reviewed every six months.

12.3.5. The effectiveness of clinical supervision should be periodically assessed. Possible effectiveness evaluation could be completed through the following:

- Staff surveys

- Measurement of occurrences of issues highlighted by the clinical leadership and addressed by the MDT though supervision

- Supervision audit and review of completeness, compliance with organisational standards for appraisal or use of evidence-based tools such as the Gallup 12 Questions Survey (Wagner \& Harter, 2006).

12.3.6. Training should be provided in the skills necessary to meet requirements of national guidance for clinical interventions.

12.3.7. Training should be provided for leaders to develop the clinical and work environment of the CAMHS PICU over time.

12.3.8. There should be an investment in the development of managerial and clinical leadership competencies of unit managers and team leader grade nurses. This leadership development programme should be in line with current national healthcare leadership frameworks.

12.3.9. The appropriate clinical lead should be accountable for providing opportunities for new staff to acquire and/or demonstrate the appropriate competencies.

12.3.10. CAMHS PICUs are encouraged to network and develop links with each other, and more widely, in order to share learning and good practice beyond their MDT.

12.3.11. Within high functioning teams, responsibility for improvement should be devolved to frontline staff, and acts of leadership can come from anyone within a healthcare team. All team members can participate in leadership development which will 
ensure that the whole workforce can have the leadership knowledge, skills and behaviours needed to improve health and care.

12.3.12. The training programme should provide the MDT with the overall ability to deal with most daily operating requirements of a CAMHS PICU.

12.3.13. All competency assessments should be repeated annually.

12.3.14. Staff should aim to take up training and development opportunities provided, over and above those legally required for each post. 


\section{Young person $\&$ carer participation}

\subsection{Rationale}

Good quality services are characterised by high levels of young person and carer participation at all levels within the organisation. Young people should be involved in decisions about their own care, and improvement of the overall CAMHS PICU management. As a wider group, young people and their families and/or carers should also be able to influence the oversight and governance of the provider organisation.

\subsection{Standard}

\section{Young person}

13.2.1. The CAMHS PICU should ensure that young people are involved in planning their own care as far as possible. This should be demonstrated and regularly monitored through locally developed feedback systems.

13.2.2. All care should be planned according to the young person's own agenda. This will include documented plans which enable the young person to understand what will need to happen in order for discharge from hospital to be achievable.

13.2.3. Young people should be provided with a schedule of care programme approach (CPA), regular ward rounds, etc.

13.2.4. Individual CAMHS PICUs should be able to demonstrate locally agreed processes for young person involvement. These should include full compliance with robust care planning procedures, use of evidence-based routine outcome measures to evaluate young person experience, and structures (such as community meetings) to have their views heard by CAMHS PICU managers.

13.2.5. Young people should be provided with written information about the unit, presented in an age appropriate 'easy read' format. Where possible, this should be available prior to admission and could be delivered electronically. It should include:

- The function of the unit, how it operates

- What they are and are not allowed to have in the unit (e.g. restricted items)

- Treatments or interventions they are offered (see 15.2.19-15.2.21)

- Education support and facilities on the unit

- Opportunities for being involved in participation work. 
13.2.6. Young people should be involved in planning how to manage their distress prior to any episodes occurring, using an 'advance directives' type model.

13.2.7. After all incidents where restrictive practices such as restraint, RT or seclusion have been employed, the young person should be given the opportunity to have a de-brief session with a member of staff (see Chapter 5).

13.2.8. The CAMHS PICU should be able to demonstrate a range of service improvements which have arisen from young person participation.

13.2.9. Young people should participate in the recruitment and appraisal of staff. There should be evidence of this, and their involvement should be audited and evaluated on an annual basis.

\section{Family and/or carers}

13.2.10. There may be a number of adults that a young person wishes to be involved in their care, in addition to those who have parental responsibility (e.g. parents, other family members such as grandparents or older siblings and foster carers). Care planning procedures should include reference to the involvement of such adults, and the agreement of those with parental responsibility should be clearly documented.

13.2.11. The CAMHS PICU should have appropriate mechanisms to engage family and/or carers with the young person's care. This should be done in a sensitive manner, bearing in mind the needs of family and/or carers from diverse backgrounds.

13.2.12. Family members and/or carers should be provided with written information about:

- Treatments or interventions that the young person is offered (see 13.2.5; 15.2.19-15.2.21)

- Education facilities (see 13.2.5; 16.2.19).

13.2.13. The CAMHS PICU should be able to demonstrate involvement of family and/or carers in the care and treatment of their young person through locally developed feedback systems.

13.2.14. Health professionals involved in the care of a young person with a mental health illness should be familiar with local and national sources of information (organisations and websites) and/or support for young people and their family and/or carers. They should be able to discuss and:

- Advise on how to access these resources

- Actively support young people and their family and/or carers to engage with these resources. 
13.2.15. Care planning and delivery should routinely involve both the young person and their family and/or carers. Occasions on which there is discussion between the clinical team and families and/or carers but not involving the young person, should be fully documented and managed according to relevant legal standards.

\subsection{Good practice guidance}

13.3.1. See Appendix 1 for suggested online resources.

13.3.2. The CAMHS PICU team should find innovative solutions to promote participation of both young people and their family and/or carers in the young person's care, and in the running of the ward.

13.3.3. Evidence of effective participation should be seen in all aspects of the ward's operations, such as: the décor, the staff recruitment, the policies and procedures, service developments and, most importantly, in individual care.

13.3.4. The unit should consider working with young people's organisations to deliver training on participation to all staff. 


\section{Partnership working}

\subsection{Rationale}

It is essential for any organisation working with young people to co-operate fully with all other services which deliver care to those young people. Their range of needs often means that this will involve a large number of organisations, and this is especially likely amongst those in need of psychiatric intensive care. The geographically dispersed nature and low numbers of CAMHS PICU add further challenges, as PICU providers may need to develop relationships over long distances and across multiple localities. Provision of health and social care is often undertaken by multiple providers beyond the traditional NHS and local authority organisations.

\subsection{Standard}

14.2.1. Care planning should form the backbone of all arrangements in ensuring that there is clear understanding between organisations as to who is doing what (see Chapter 2).

14.2.2. The CAMHS PICU should engage routinely with all relevant external agencies from the young person's local area that are involved in their care, ensuring that they can input into the patient's current care plan. This should include the relevant local area social services team, education provider, mental health service, educational agencies, the Family Court, child and family social services, therapists specialising in family work, advocacy services and any other relevant voluntary or community sector organisations who may be working with the young person, their family and/or carers.

14.2.3. The CAMHS PICU should interface with clinical services which account for the medical and psychiatric needs of young people.

14.2.4. There should be clear procedures for escalation where a necessary service is identified as not being provided by another organisation.

14.2.5. The education professionals within the hospital should ensure routine engagement with the young person's regular school or college to optimise educational outcomes (see Chapter 16).

14.2.6. Any difficulties surrounding communication with schools and colleges must be immediately escalated via the relevant local authority. 
14.2.7. Information sharing procedures should be in place which ensure information relevant to the young person's health and well-being can be shared between organisations

14.2.8. If a young person is 17 years old or older during their admission, the CAMHS PICU team should liaise with the community team to ensure that the necessary arrangements are in place for transition to adult services.

\subsection{Good practice guidance}

14.3.1. The CAMHS PICU should have a culture which is outward looking and able to engage with a large range of organisations which might be involved in providing services to young people.

14.3.2. A model of co-operation should be evident in care planning, clinical interventions, discharge planning and participation.

14.3.3. Young people using the service should be able to describe the unified efforts of professionals helping them in a manner in which organisational boundaries are not evident. 


\section{Prescribing practices}

\subsection{Rationale}

Treating young people in a CAMHS PICU will undoubtedly involve the use of medicines. All members of the MDT involved in the prescribing and administration of medicines should be competent and familiar with medicines used in this context. Any treatment in CAMHS PICUs, including pharmacological treatment, should be intensive, multidisciplinary and evidencebased, directed towards rapidly reducing acute psychiatric symptoms whilst promoting selfmanagement and recovery.

\subsection{Standard}

15.2.1. Where possible, the choice of medication should be made jointly by healthcare professionals and either the family and/or carers of younger children, or the young person, their family and/or carers (NICE, 2013).

15.2.2. The medical team is primarily responsible for prescribing and monitoring medications. This also includes reviewing adverse effects and dosages to ensure optimal outcome for the patient.

15.2.3. 'Start low and go slow' is a helpful principle by which to prescribe for young people. Especially with antipsychotics, in some cases it is advisable to start at dosages well below the minimum therapeutic dose according to the manufacturer (e.g. risperidone $0.25 \mathrm{mg}$; aripiprazole 1-2 mg), slowly increasing according to response and tolerability. The aim is to always keep the young person on the lowest possible effective dose.

15.2.4. Polypharmacy and the use of above-BNF dosages of medications should be avoided as far as possible. However, when they are used, there must be a clear documented rationale made by a specialist psychiatrist or pharmacist; there should be regular review of such practice.

\section{The prescriber's responsibilities}

15.2.5. Prescribers should be familiar with using the BNF and BNF for Children (BNFc), and the guidance within them (http://www.bnf.org). The BNFc provides information on the use of medicines in children ranging from neonates to adolescents. These texts contain essential information for the safe, effective and appropriate use of medicines in young people, from the prescribing, monitoring, supply, and administration. The 
prescribing notes in the BNFc provide an overview of the drug management of common conditions and facilitate rapid appraisal of treatment options. Advice issued by NICE is integrated within BNFc prescribing notes if appropriate.

15.2.6. Medicines' reconciliation should be completed on admission by a prescriber; a pharmacist should be involved (NICE, 2015b).

15.2.7. Appropriately qualified and senior medical staff should lead the ongoing formulation of a pharmacological treatment plan. This should occur with input from the young person, their family and/or carers, and the MDT.

15.2.8. There should be an active review of all prescribed medicines at least once a week, in the MDT review meeting with the consultant psychiatrist and other members of the MDT, ensuring that those who need medicines get optimal regimes.

\section{Pharmacology}

15.2.9. Young people are not small adults, therefore the medicines prescribed for them need to be carefully tailored according to a range of factors. Drug selection should aim to minimise the potential for drug accumulation, adverse drug reactions, and exacerbation of any pre-existing disease.

15.2.10. Pharmacokinetic changes in childhood are important and have a significant influence on drug handling and need to be considered when choosing an appropriate dosing regimen for a young person. Factors such as gastric $\mathrm{pH}$ and emptying time, intestinal transit time, immaturity of secretion and activity of bile and pancreatic fluid among other factors determine the oral bioavailability of medicine in paediatric and adult populations. Anatomical, physiological and biochemical characteristics in young people also affect the bioavailability of other routes of administration (Fernandez et al. 2011).

15.2.11. Young people appear to be at higher risk than adults of a number of adverse effects, such as extra-pyramidal side effects (EPS) and metabolic and endocrine abnormalities (Vitiello et al. 2009). There is a higher incidence of disinhibition or paradoxical reactions with benzodiazepines in young people when compared to adults.

15.2.12. A young person's current details such as age, weight and surface area should be accurately recorded and considered to ensure appropriate dosing. A young person's weight and surface area may change significantly in a relatively small time period. 


\section{Medico-legal implications}

\section{(see also Chapter 10)}

15.2.13. Young people in CAMHS PICUs are likely to be detained under the MHA 1983. With regards to medication, practitioners should be familiar with the MHA 1983 Code of Practice (Department of Health, 2015), especially with chapters 19 (Children and young people under the age of 18), 24 (Medical treatment) and 25 (Treatments subject to special rules and procedures).

15.2.14. Other relevant legal frameworks are the Children Act 1989, 2004, the Mental Capacity Act 2005, the Family Law Reform Act 1969, the Human Rights Act 1998 and the United Nations Convention on the Rights of the Child.

The term unlicensed medicine is used to describe medicines that are used outside the terms of their UK product licence or which have no UK licence. A licence is a marketing authorisation issued by a regulatory body (the Medicines and Healthcare Products Regulatory Agency (MHRA) in the UK and the European Medicines Agency (EMA) for the European Union) and will contain a summary of product characteristics (SPC).

The term off-label prescribing refers to the use of licensed medicines outside of its licence (e.g. for a different indication, at a higher dose). Off-label prescribing occurs quite often in young people, as most medicines were only tested in clinical trials in adults and therefore are only licensed for use in adults. Adverse reactions are more common during off-label prescribing, partly because dosing schedules for medicines developed for use in adults have often not been assessed in young people.

15.2.15. Prescribers should refer to the BNFc's advice on the use of unlicensed medicines and the 'off-label' use of licensed medicines. Prescribing an unlicensed medicine or 'off-label' alters and increases the prescriber's professional responsibility and potential liability. The prescriber should be able to justify and feel competent in using such medicines.

15.2.16. It is recognised that clinicians may decide that the use of medication outside of the SPC (i.e. 'off-label') is occasionally justified, bearing in mind the overall risks. However, where the regulatory authorities or manufacturer issues a specific warning that this may result in an increased risk of fatality, the medication should only be used strictly in accordance with the current marketing authorisation. 
15.2.17. If the prescriber decides to prescribe an unlicensed medicine, this should be based on an assessment of the individual patient, and where it is deemed necessary to do so to meet the needs of the patient.

15.2.18. In line with General Medical Council (GMC) guidance, when prescribing an unlicensed medicine the prescriber must:

- Be satisfied that there is sufficient evidence or experience of using the medicine to demonstrate its safety and efficacy

- Take responsibility for prescribing the medicine and for overseeing the patient's care, monitoring, and any follow up treatment, or ensure that arrangements are made for another suitable doctor to do so

- Make a clear, accurate and legible record of all medicines prescribed and, where the prescriber is not following common practice, the reasons for prescribing an unlicensed medicine

- Give the young person (or their family and/or carers) suitable information about the medicine that it is proposed to prescribe, to allow them to make an informed decision.

\section{Providing young people with information about their medicines}

15.2.19. When communicating with young people and their family and/or carers, prescribers and other healthcare professionals should (NICE, 2013):

- Take into account the young person's developmental level, emotional maturity and cognitive capacity including any learning disabilities, sight or hearing problems or delays in language development

- Use plain language where possible and clearly explain any clinical language

- Check that the young person and their family and/or carers understand what is being said

- Use communication aids (e.g. pictures, symbols, large print, braille, different languages or sign language) if needed. 
15.2.20. Prescribers and other healthcare professionals should provide age-appropriate information and discuss and explain the likely benefits and possible side effects of each medicine, including (NICE, 2013):

- Metabolic (including weight gain and diabetes)

- Extrapyramidal (including akathisia, dyskinsesia and dystonia)

- Cardiovascular (including prolonging the QT interval)

- Hormonal (including increasing the plasma prolactin)

- $\quad$ Other (including unpleasant subjective experiences).

15.2.21. Prescribers should provide young people with psychosis or schizophrenia, and their family and/or carers, with comprehensive written information about:

- The nature of, and interventions for, psychosis and schizophrenia (including biomedical and psychosocial perspectives on causes and treatment, and any relevant public information booklets) in an appropriate language or format

- Support groups, such as third sector organisations (including voluntary ones).

\section{Monitoring}

15.2.22. Before starting antipsychotic medication, the following baseline investigations should be taken and recorded (NICE, 2013):

- Weight and height (both plotted on a growth chart)

- Waist and hip circumference

- Pulse and blood pressure

- Blood tests:

Fasting blood glucose

Glycosylated haemoglobin ( $\mathrm{HbA1c})$

Blood lipid profile

Prolactin levels

Urea \& electrolytes (U\&Es)

Liver function test (LFT)

Thyroid function test (TFT)

Erythrocyte sedimentation rate (ESR)

C-reactive protein (CRP)

Calcium (Ca)

- Assessment of any movement disorders

- Assessment of nutritional status, diet, and level of physical activity. 
15.2.23. Monitor and record the following regularly and systematically throughout treatment with antipsychotics, but especially during titration (NICE, 2013):

- Efficacy, including changes in symptoms and behaviour

- Side effects of treatment, taking into account overlap between certain side effects and clinical features of schizophrenia

- The emergence of movement disorders

- Weight, weekly for the first 6 weeks, then at 12 weeks, and then every 6 months (plotted on a growth chart)

- Height every 6 months (plotted on a growth chart)

- Waist and hip circumference every six months (plotted on a centile chart)

- Pulse and blood pressure (plotted on a centile chart) at 12 weeks and then every 6 months

- Fasting blood glucose, $\mathrm{HbA1c}$, blood lipids and prolactin levels at 12 weeks, and then every 6 months

- U\&Es, LFTs, TFTs, ESR, CRP and Ca every 6 months

- Adherence

- Physical health.

\section{Antipsychotic induced hyperprolactinaemia}

15.2.24. If prolactin levels are greater than $900 \mu \mathrm{g} / \mathrm{L}$, depending on clinical need and risk assessment, the following options should be considered:

- Gradually reduce dose of antipsychotic

- Slowly cross taper to aripiprazole

- Add low dose of aripiprazole as treatment for hyperprolactinaemia.

15.2.25. Should prolactin levels not return to normal with the above measures, a brain MRI scan should be considered, in order to rule out a prolactinoma. A consultation with a paediatric endocrinologist is also recommended. 


\section{Rapid tranquillisation}

(see also Chapter 5; NICE, 2015a)

15.2.26. The aim of RT is to achieve a state of calm sufficient to minimise the risk posed to the young person or to others. RT should not be used to treat the underlying psychiatric condition.

15.2.27. Environmental and situational factors can influence behaviours and need to be considered and addressed (e.g. through de-escalation techniques).

15.2.28. All CAMHS PICUs should have a local RT guideline specifically addressing RT in young people.

15.2.29. When $\mathrm{RT}$ is prescribed for a young person, the choice of medicine(s) and the dose(s) should be tailored to the individual. This will be dependent on several factors including: the young person's age; concomitant physical disorders, such as renal, hepatic, cardiovascular or neurological); and concomitant medication, such as stimulants for attention deficit hyperactivity disorder (ADHD), or illicit substance use (legal highs).

15.2.30. Oral medication should be offered before parenteral treatment is administered, although parenteral medication has a faster onset of action. It may be appropriate to consider the formulation that the young person is willing to accept. For example, a number of the newer antipsychotics are available as soluble or disintegrating tablets (aripiprazole, risperidone and olanzapine) and liquids (amisulpride, aripiprazole and risperidone).

15.2.31. As with all patients receiving medication as RT, a young person must be informed that medication is going to be given and must be given the opportunity at any stage to accept oral medication voluntarily. In young people who are not Gillick competent, family and/or carers should be informed of the situation and consent sought for such treatment. It is good practice to inform both the young person and their family and/or carers.

15.2.32. In certain circumstances, current BNF/BNFc uses and limits, and the manufacturer's SPC may be knowingly exceeded (e.g. for oral lorazepam). This decision should not be taken lightly or the risks underestimated. Prescribers should record a risk vs benefit analysis in the case notes and a rationale in the care plan. Where the risk vs benefit is unclear, advice should be sought from clinicians not directly involved in the young person's care. 
15.2.33. Following RT, the young person should be calm and still able to participate in further assessment and treatment. It is important to undertake frequent and intensive monitoring of a calmed young person, paying particular attention to regular checks of airway, level of consciousness, pulse, blood pressure, respiratory effort, temperature and hydration.

15.2.34. When prescribing medication to prevent or control violence the following guidelines should be followed:

- Medication should not be used to manage aggression caused by identifiable environmental factors and the use of other therapies

- Medication should only be used when the risk of not using medication is judged to be greater than that arising from its use

- The indication for any PRN medication prescribed should be clearly stated

- The lowest dose compatible with effective treatment should be used

- The dose prescribed should be individually tailored for each patient, taking into consideration comorbid physical disorders, concomitant medication, history of illicit substance use, bodyweight, age and hydration status

- The choice of medication used should also be individually tailored to the young person and informed by a knowledge of their psychiatric and medical history, mental and physical state, treatment history, any existing advance directive and after an attempt has been made to establish a provisional diagnosis

- The least number of medicines should be used, and combinations from the same class of medicine avoided

- The young person should be regularly monitored for side effects of the medication, and both regular and PRN medication should be reviewed on a regular basis

- If there is evidence that medicines prescribed are unnecessary or ineffective they should be reduced and discontinued

- The use of medicines outside their licence, or above the maximum recommended dosage (either alone or in combination) is the responsibility of the individual prescriber who should undertake the recommended safeguards in relation to documentation of proposed indication and consent. 


\section{Prescribing \& the role of the pharmacist}

15.2.35. Multidisciplinary discussions and interdisciplinary consultations should lead to safer decisions in prescribing. From the discussion and decision making conversation to the administration of any particular medicine, there is a process in which several MDT members may be involved. It is the responsibility of all members to ensure that prescribing standards are met at each step of the process, from the writing in prescription charts to the administration of the drug and adherence strategies.

15.2.36. A specialist mental health pharmacist working in the CAMHS PICU should have a good understanding of the general pharmacological management of the acute presentations of mental disorder and acute disturbance in young person patient groups. They should work with other professionals in the CAMHS PICU to ensure a high standard of medicines management.

15.2.37. There should be provision for a specialist mental health pharmacist to visit the CAMHS PICU several times a week and take part in the weekly MDT reviews. Many medicines will need to be reviewed on a daily basis, and the pharmacist needs to visit the CAMHS PICU frequently enough to do this with prescribing colleagues, focusing on their therapeutic as well as adverse effects.

15.2.38. The specialist mental health pharmacist should be able to provide medicines information tailored to the needs of the young people and their family and/or carers on the nature of, and interventions for, pharmacological treatment prescribed for the young person.

\section{Training \& competency of staff}

15.2.39. Prescribers and other healthcare professionals involved in the use of medicines must be able to use BNFc effectively, and keep up to date with significant changes in the use of medicines relevant to their area of clinical practice.

15.2.40. Healthcare professionals responsible for the CAMHS PICU should ensure that there is a defined and well understood procedure for recognising and closely monitoring side effects from prescribed medication. The CAMHS PICU should keep, maintain and update skills required to implement a number of evidence-based, validated side effect assessment scales (either clinically assessed or self-reported).

15.2.41. All staff involved in administering or prescribing RT, or monitoring young people to whom parenteral RT has been administered, should receive ongoing competency training to a minimum of Immediate Life Support (covering: airway, cardio-pulmonary 
resuscitation (CPR) and use of defibrillators; Nolan, 2010). Staff who undertake physical intervention/restraint or seclusion should as a minimum be trained in basic life support (Nolan, 2010).

\subsection{Good practice guidance}

15.3.1. CAMHS PICUs should participate in relevant national audits and surveys of prescribing practices in order to benchmark their services, contribute to the wider dataset and understanding of current practice, and help shape future service delivery. For example, by using QNIC standards and Prescribing Observatory for Mental Health (POMH) audits (see Chapter 18).

15.3.2. Further guidelines on the use prescribing for RT can be found in NICE (2015a).

15.3.3. See Appendix 1 for online resources. 


\section{Education model}

\subsection{Rationale}

The UK Government's policy intention is that all children, regardless of circumstance or setting should receive a good education to enable them to shape their own futures. This vision includes CAMHS PICUs, therefore all providers of such services should ensure that they have systems and processes in place so that the young people in their care have access to good quality education on a par with that of mainstream schools, along with the support needed to overcome barriers to attainment. This includes their social and emotional needs.

The support will need to be tailored to meet the young person's current needs whilst they are acutely suffering from mental health issues. The young person's mental state will impact on the team's ability to deliver education.

Educational provision, and the support framework which surrounds it, should enable a young person to maintain academic progression and attainment, and allow them to thrive and prosper in the education system.

\subsection{Standard}

16.2.1. A young person of compulsory school age (5-16 years) admitted to a CAMHS PICU should have access to suitable full-time education (or as much education as the young person's health condition allows).

16.2.2. A young person who is unable to attend school because of health needs should be able to access suitable and flexible education appropriate to their needs. The nature of the provision must be responsive to the demands of what may be a changing health status.

16.2.3. The CAMHS PICU must comply with the requirement for registration with the Department for Education for any school or establishment where full time education is provided for:

- Five or more pupils of compulsory school age or

- One or more such pupils with an Education, Health and Care Plan or

- One or more such pupils who are 'looked after' by the local authority.

16.2.4. It is important that young people do not miss the opportunity to sit examinations at the same time as their peers, even if they are admitted to a CAMHS PICU at the 
appropriate time. However, examinations can be deferred and taken at a later date if needed. The CAMHS PICU should contact the Joint Council for Qualifications (JCQ; http://www.jcq.org.uk/) and complete the straightforward process to become a registered examination centre.

16.2.5. A young person who has ceased to be of compulsory school age but has not yet reached the age of 18 (or attained a level 3 qualification), is under a duty to participate in education or training and their needs should be assessed and accommodated if practicable. Young people who are aged 16 or over and are unwell have the same rights to education as those under the age of 16 .

16.2.6. Education providers within the CAMHS PICU should make good links, and work in partnership, with the local authority (independent schools and alternative provision, maintained schools, academies or free schools) to consider social and emotional needs, for example ensuring that a young person who is at school feels fully part of their school community, is able to stay in contact with classmates, and have access to the opportunities enjoyed by their peers.

16.2.7. This wider support framework surrounding the young person should work cohesively across organisational boundaries, and include a structured assessment of the needs of the young person, and appropriate referral and re-integration plan that focuses on the young person's interest and appropriate outcomes rather than processes.

16.2.8. The CAMHS PICU should work with relevant local authorities, schools, providers and commissioners to ensure the best outcomes for a young person. The local authority has a statutory obligation to provide funding for the education of all young people. The Children and Families Act 2014, Section 19 of the Education Act 1996 and the Equality Act 2010 are key reference points which need to be referred to when planning the education provision for young people with mental health needs.

16.2.9. The sharing of information between a young person's school and the CAMHS PICU is important. If a young person is at school, the CAMHS PICU education staff should liaise with the school to ensure that the provision offered to the young person is as effective as possible, continuity is maintained where possible, and that the young person can be reintegrated back into their school successfully on discharge from hospital.

16.2.10. Each young person should be provided with written information about education presented in a way that they can understand. 


\section{Resources}

16.2.11. The use of electronic media (e.g. 'virtual classrooms', learning platforms) can provide access to a broader curriculum, but this should generally be used to complement face-to-face education, rather than as sole provision.

16.2.12. Each young person should have access to the materials required to continue with their education (e.g. textbooks, DVDs, internet).

\section{Educational staff}

16.2.13. The CAMHS PICU should have access to a range of educational staff (see Chapter 11).

16.2.14. Teachers who provide education in the CAMHS PICU should receive suitable training, supervision and support (see also 12.2.21-12.2.36):

- To enable them to comply with the current requirements of the National Curriculum

- In the management of violence and aggression.

16.2.15. Education staff should be given relevant information relating to a young person's health condition, and the possible effect the condition and/or medication taken has on the young person.

16.2.16. Teachers should regularly attend and contribute to MDT meetings (see Chapter 11).

\section{Teaching}

16.2.17. Teaching staff should complete an assessment of each young person's educational needs which is reviewed at each CPA (or similar) review.

16.2.18. Teaching staff should ensure that each young person has an appropriate individual learning plan (ILP) or individual curriculum plan (ICP).

16.2.19. Teaching staff should maintain communication with the young person's family and/or carers.

16.2.20. Where there are significant barriers to learning, working in partnership with the young person's school or college and local authority the CAMHS PICU education team should investigate the possibility of instigating a Statutory Assessment for an Education, Health and Care Plan (Children and Families Act 2014).

16.2.21. The CAMHS PICU should provide the core educational subjects of maths, English and science. 


\subsection{Good practice guidance}

16.3.1. See Appendix 1 for online guidance suggestions.

16.3.2. The CAMHS PICU should provide the full National Curriculum (or equivalent) at the appropriate key stages.

16.3.3. Where appropriate and practical, young people over 16 should be able to continue with their Key Stage 5 education.

16.3.4. The education provision should have a website that the young person and their family and/or carers can access before admission.

16.3.5. Educational outings should be provided as appropriate. 


\section{Equality \& diversity}

\subsection{Rationale}

Some complex and/or long-term health issues may be considered disabilities under equality legislation. CAMHS PICUs have the responsibility to ensure that all young people receive equality of treatment without prejudice or discrimination. This is underpinned by wider national policies and local organisational guidelines. The principles of equality apply to the whole CAMHS PICU: to staff, patients, carers and others who interface with the unit. Additional interventions may be required in order to meet the specific needs of individuals to achieve an equitable outcome.

\subsection{Standard}

17.2.1. Disabled young people should not be discriminated against and the CAMHS PICU should foster equality of opportunity for disabled young people as well as good relations between disabled and non-disabled young people.

17.2.2. All agencies should make reasonable adjustments to alleviate any disadvantages faced by disabled young people, and plan to increase disabled access.

17.2.3. The organisation in which the CAMHS PICU operates should have clear policies relating to fair and equal treatment of all staff and patients based on national guidance, employment law and professional expectations.

17.2.4. The expectation is that all CAMHS PICU staff should have undertaken the local mandatory equality and diversity training.

17.2.5. It is the responsibility of senior managers to engender a culture of embracing equality.

17.2.6. An outline of fair and equal treatment should be incorporated into the local CAMHS PICU operational policy and into a welcome pack for patients as part of the overall philosophy of care.

17.2.7. Nationally there should be sufficient provision of, and access to, CAMHS PICU services such that young people are not discriminated against.

17.2.8. Specific patient needs should be established either before admission or as soon after as possible as these potentially impact the young person's care and treatment plan as well as level of risk. 
17.2.9. All communication with each young person, verbal or written, should be undertaken or provided in a way that is suitable to their age and in a way that they can understand.

17.2.10. Where necessary, interpreters should be provided to allow full and equal participation of both the young person and their family and/or carers.

17.2.11. All ward information should be available in a relevant range of languages and media suitable to facilitate good communication and understanding between young person, carers and health professionals.

17.2.12. The communication needs of people with sensory impairment should also be considered, and appropriate support should be in place for these patients during their admission.

17.2.13. The CAMHS PICU should strive to offer services to meet the needs of individual patients. For example, where possible, amenities and/or resources such as a multifaith room and food suitable for a range of special dietary requirements should be provided.

17.2.14. Assumptions about the young person based on their gender, culture, ethnicity, sexuality or other personal characteristics should be avoided.

17.2.15. The CAMHS PICU should access the expertise and support of local religious, cultural and pastoral services to respond to patients' spiritual needs.

17.2.16. Regular training in addressing inequality issues and developing cultural competence should be available to all staff.

17.2.17. The CAMHS PICU team should be aware of relevant ethnic religious festivals and to be sensitive to the needs of individual patients wishing to observe these festivities.

17.2.18. Where a CAMHS PICU is mixed gender, the design, layout and procedures should be compliant with national standards for the provision of mixed sex accommodation (Department of Health, 2010).

17.2.19. Care plans should incorporate aspects of specific cultural, ethnic, gender specific care provision necessary to facilitate needs where possible. The care plans should be recovery-focused and sensitive to the diverse aspects and protected characteristics of the individual.

17.2.20. The Equality Act 2010 places a statutory responsibility on all organisations to make 'reasonable adjustments' to avoid discrimination against people with learning 
disabilities (LD). However, there remains debate as to whether the psychiatric care for people with LD, and particularly those who present with co-morbid mental illness, should be undertaken by mainstream services as per the normalisation agenda (as championed by the Department of Health, 2001b) or whether the specific needs of such a complex group preclude their effective care and treatment outwith specialist services.

17.2.21. When people with LD are admitted to inpatient services there are clear risks that they may be vulnerable, marginalised, and their admission may be prolonged (Bouras \& Holt, 2004). There is a group of LD patients whose involvement with secondary and tertiary inpatient services is triggered by acute mental illness. Where their level of need meets the necessary criteria, admission to a CAMHS PICU service will be wholly appropriate. Such admissions should be as brief as possible. This can be helped by appropriate staff awareness training, good liaison between inpatient and community services, up to date health action plans, access to advocacy services and support from community LD assessment and/or treatment services. Support will be particularly relevant for individuals with adaptive or language deficits or an underlying pervasive developmental disorder (NDTi, 2012).

17.2.22. The CAMHS PICU team should reflect on regular reviews of patient demographics and the use of the MHA 1983 (see also 18.2.19) to create an appropriate environment in which to provide a responsive service.

\subsection{Good practice guidance}

17.3.1. All organisational and CAMHS PICU policies within organisations which facilitate PICU care should be aligned to treating in the most holistic way possible, relating to age, ethnicity, culture, individual need and respecting any protected characteristic.

17.3.2. Within the CAMHS PICU environment, whilst risk assessed, all aspects of individual need pertaining to treatment should be addressed as fully as possible without prejudice or discrimination.

17.3.3. National resources (e.g. Care Quality Commission, 2011) should be used to provide a framework for the MDT to develop best practice and reduce inequality. 


\section{Quality improvement, clinical audit \& assessments}

\subsection{Rationale}

Clinical audit is at the heart of clinical governance and is an essential tool in raising the quality of care through:

- Assessing the quality of practice against agreed standards

- Highlighting areas of concern regarding the quality and cost-effectiveness of patient care

- Improving practice through informed feedback

- Being an integral part of service culture in order to monitor service responsiveness to the various aspects of patient care.

\subsection{Standard}

18.2.1. All mandatory and statutory programmes of audit and performance assessments should be completed by the CAMHS PICU at the required frequency. Results should be shared amongst the reams and local services. Good performance should be appropriately acknowledged and encouraged.

18.2.2. The CAMHS PICU should participate fully in relevant organisation-wide audits of practice.

18.2.3. Audits should be carried out at various different levels of operational delivery to ensure that conditions and delivery meet the required national and local standards.

18.2.4. Results of clinical audit should be disseminated to all staff, local teams and other stakeholders. Good performance should be appropriately acknowledged and commended. If results show less than satisfactory practice, local action plans should be put into place and enacted to rectify situations as needed. Recommendations and commendations should be made to inform further quality improvements in the service.

18.2.5. All audits which involve young people's personal information should be subject to relevant governance and appropriate ethical approval as necessary.

18.2.6. The MDT members responsible for audit and monitoring should adhere to the regulations of the Data Protection Act 1998 and supplementary documents. 
18.2.7. The MDT member responsible for overseeing each clinical audit should have a good understanding of the function, methods and application of clinical audit.

18.2.8. All clinical staff are expected to participate in quality improvement activities (such as clinical audit) not just managers of the CAMHS PICU, or senior staff.

18.2.9. Young people, their family and/or carers should be involved in the process of clinical audit as far as possible.

18.2.10. Examples of different types of audit and assessments are described below.

\section{Extra-organisational}

18.2.11. The CAMHS PICU should participate in national programmes of audit (e.g. audits of MHA 1983 compliance; CPA (or similar) reviews; environmental audits such as: Patient Environment Action Team (PEAT) or Patient Lead Assessment of the Care Environment (PLACE)), assess the delivery and quality of services (e.g. CQC compliance assessments; the reporting and monitoring of incidents; the use of RT), and contribute to national information gathering (e.g. average length of stay and readmission rates).

\section{Organisational}

18.2.12. Each organisation should have a policy for the management of controlled drugs (CDs). The organisation's named accountable officer for CDs is responsible for ensuring that CDs are used in line with the organisation's CD policy, that audits of storage and use of CDs are regularly completed and fulfil legislative requirements, including in the CAMHS PICU.

18.2.13. The organisation should have a policy and method for routinely reporting incidents, and interrogating the data at an organizational and unit level. Staff should report all incidents in accordance with the organisation's serious untoward incident (SUI) policy, and encourage a similar practice amongst other healthcare professionals.

18.2.14. There should be at least an annual health and safety visit to the CAMHS PICU, including an executive board member of the organisation.

18.2.15. The CAMHS PICU should complete annual infection control audits.

18.2.16. The organisation should have a medicines policy describing local practice, to adhere to legislative standards. The CAMHS PICU is responsible for adhering to the 
standards of safe and secure handling of medicines and for regularly participating in local audits in line with this policy.

18.2.17. The organisation should have a policy and specified standards for mandatory staff training. The CAMHS PICU should have a method for recording compliance with these standards.

18.2.18. The organisation should have a policy and specified standards for staff supervision. The CAMHS PICU should have a method for recording supervision and adherence to these standards (see Chapter 12).

18.2.19. The CAMHS PICU should review the demographic background of patients with the use of the MHA 1983, and compare the results with national or regional benchmarks (see also 17.2.22).

18.2.20. The CAMHS PICU should have a mechanism for recording the service experience of young people and their family and/or carers.

18.2.21. The CAMHS PICU should monitor the frequency of one-to-one care for the young person with their named nurse or key worker.

18.2.22. The CAMHS PICU should review the overall number and pattern of incidents occurring in the unit, as well as the number and patterns of medication errors, verbal and physical abuse, complaints and praise.

18.2.23. The CAMHS PICU should monitor the overall number and pattern of incidences of restraint, successful de-escalation (or attempts to de-escalate), RT, seclusion and length of any seclusions.

18.2.24. Positive lessons should be learned from the results of incident audits and complaints received, and any serious issues escalated from ward to board level within the organisation.

18.2.25. The CAMHS PICU should ensure that young people are involved in planning their own care and that this is routinely monitored.

18.2.26. Young people's involvement in recruitment should be audited and evaluated on an annual basis. 


\subsection{Good practice guidance}

18.3.1. CAMHS PICUs should participate in relevant national audits and surveys of practice in order to benchmark their services, to contribute to the wider dataset and understanding of current practice, and to help shape future service delivery. For example, by using QNIC standards, Prescribing Observatory for Mental Health (POMH) audits and NHS Benchmarking (see Chapter 15).

18.3.2. Essential high risk activities should be routinely accurately documented, audited and reviewed to ensure good clinical practice and positive learning. These activities could include:

- Restraint

- Seclusion and other restrictive practices

- $\mathrm{RT}$

- Off-label use of medicines and use of unlicensed medicines

- Presence and use of equipment and medicines for the treatment of medical emergencies

- Adverse incidents and 'near misses'.

18.3.3. Standards set in this document should be selected for auditing.

18.3.4. As a key tool in delivering clinical governance, clinical audit should be part of routine practice within a CAMHS PICU. Higher levels of risk, loss of liberty and legal status of young people suggests a greater need for clinical audit and monitoring than usual, with particular attention paid to areas such as nursing observation, seclusion, restraint and RT.

18.3.5. For clinical audit to be successful, the MDT needs to give full co-operation to the implementation of the audit process including incident reporting, review of incidents and 'near misses' and generation of good practice principles. This process should be based on a reflective learning approach to practice so that positive learning can occur from mistakes. 


\section{Acknowledgements}

These standards were overseen by the NAPICU Executive and led by:

Mathew Page NAPICU Director of Policy (Project Lead and Lead Author)

Caroline Parker NAPICU Director of Operations Programmes

The authors would like to thank the individuals and organisations who have contributed to the development of these standards and worked tirelessly in the pursuit of high quality within psychiatric intensive care.

\section{Individuals}

Dr Bisharda Angom

Dr Shanika Balachandra

Dr Kevin Beardsworth

Sudha Boojhowon

Andrew Caine

Sarah Crawley

Dr Enys Delmage

Dr Ernest Gralton

Dr Amy Harrison

Kris Irons

Gill Jackson

Andy Johnston

Thomas Kearney

Dr Faeza Khan

John Palfreyman

Dr Stephen Pereira

Dr Katya Polyakova-Nelson

Dr Kavita Praveen
North Essex Partnership NHS Foundation Trust

Consultant Psychiatrist, Central \& North West London NHS Foundation Trust

Consultant Clinical Psychologist, North Essex Partnership NHS Foundation Trust

Senior Occupational Therapist, Central \& North West London NHS Foundation Trust

Clinical Quality Lead, CAMHS Priory Hospital, Cheadle Royal

Healthcare Projects Manager, Priory Healthcare

Consultant in Adolescent Forensic Psychiatry, St Andrew's Northampton

Consultant Forensic Psychiatrist, St Andrew's Healthcare

Clinical Psychologist, Ellern Mede Ridgeway, London; Lecturer in Psychology, School of Psychotherapy \& Psychology, Faculty of Humanities, Arts \& Social Sciences, Regent's University, London

Service Line Director, CAMHS

Head of Education, St Aubyn Centre

NAPICU Executive Member

NAPICU Executive Member

Consultant Psychiatrist, CAMHS PICU, Priory Hospital, Cheadle Royal

Major Projects Director, Priory Healthcare

NAPICU Chairman

Consultant Psychiatrist, The Huntercombe Group

Consultant Child \& Adolescent Psychiatrist, St Andrew's Healthcare 
Dr Rafik Refaat

Lorna Sam

Dr Alex Sales

Dr Faisil Sethi

Adel Shirbini

Sally Thomas

Dr Victoria Thomas

Paula Ward

Dr Simon Wilkinson

Vanessa Wilkinson
Consultant Child \& Adolescent Psychiatrist, East London NHS Foundation Trust

Advanced Specialist Mental Health Pharmacist, Chelsea \& Westminster NHS for Central \& North London NHS Foundation Trust

Consultant Child \& Adolescent Psychiatrist, Tavistock \& Portman NHS Foundation Trust

NAPICU Vice Chairman

Headteacher, Ellern Mede Hospital School, London

Editorial consultant

Consultant Child \& Adolescent Psychiatrist, Northumberland, Tyne \& Wear NHS Foundation Trust

Unit Manager, CAMHS PICU, Priory Hospital, Cheadle Royal

Consultant Child \& Adolescent Psychiatrist, South London \& Maudsley NHS Foundation Trust

Regional Manager, Priory Education

Young People from a Gloucester Participation User Group

\section{Organisations who were consulted}

(in alphabetical order)

\section{Barnardos}

Centre for Mental Health

College of Mental Health Pharmacy

College of Occupational Therapists

Department of Health

Faculty of Child and Adolescent Psychiatry, Royal College of Psychiatrists

Mental Health Network

\section{NHS England}

Quality Network for Inpatient CAMHS (QNIC)

Rethink

Royal College of Nursing

Young Minds
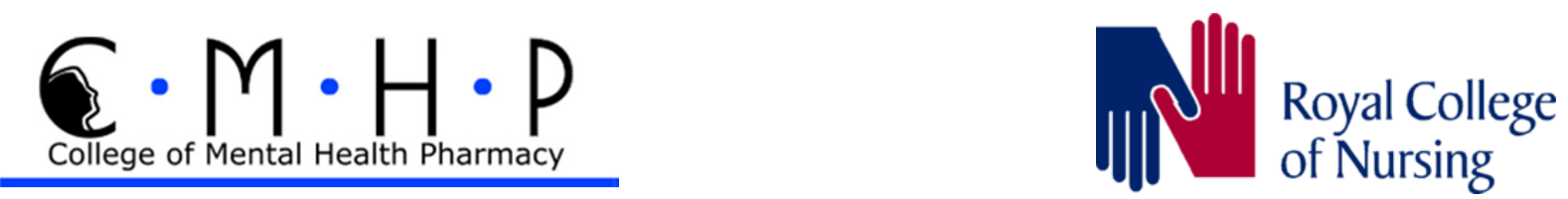


\section{References}

Bouras, N. and Holt, G. (2004) Mental health services for adults with learning disabilities. British Journal of Psychiatry. 184: 291-292. doi:10.1192/bjp.184.4.291

Care Quality Commission (2011) Count me in 2010.

http://www.cqc.org.uk/sites/default/files/documents/count_me_in_2010_final_tagged.pdf

Children Act (1989 c. 41) London: The Stationery Office.

http://www.legislation.gov.uk/ukpga/1989/41/contents

Children Act (2004 c. 31) London: The Stationery Office.

http://www.legislation.gov.uk/ukpga/2004/31/contents

Children and Families Act (2014 c. 6) London: The Stationery Office.

http://www.legislation.gov.uk/ukpga/2014/6/contents/enacted

Clarke, H. and Thompson, P. (in press) Quality Network for Inpatient CAMHS: service standards. Eighth edition. Royal College of Psychiatrists. CCQI208.

College of Occupational Therapists (2012) Occupational therapists' use of occupation-focused practice in secure hospitals. Practice Guideline.

https://www.cot.co.uk/sites/default/files/publications/public/P172-Secure-hospitals-guideline.pdf

Data Protection Act (1998 c. 29) London: The Stationery Office.

http://www.legislation.gov.uk/ukpga/1998/29/contents

Department for Constitutional Affairs (2007) Mental Capacity Act 2005: code of practice. London: The Stationery Office. 301 pp. https://www.justice.gov.uk/downloads/protecting-thevulnerable/mca/mca-code-practice-0509.pdf

Department for Education (2013) Alternative provision: statutory guidance for local authorities. 14 pp. http://www.education.gov.uk/aboutdfe/statutory/g00211923/alternative-provision

Department of Health (2001a) Seeking consent: working with children. 25752. Gateway ref. 2001. London: Department of Health Publications. $34 \mathrm{pp}$.

http://webarchive.nationalarchives.gov.uk/20130107105354/http:/www.dh.gov.uk/prod_consum_dh/gr oups/dh_digitalassets/@dh/@en/documents/digitalasset/dh_4067204.pdf

Department of Health (2001b) Valuing people: a new strategy for learning disability for the $21^{\text {st }}$ century. Cm 5086. London: Department of Health. 149 pp.

https://www.gov.uk/government/uploads/system/uploads/attachment_data/file/250877/5086.pdf

Department of Health (2008) High quality care for all: NHS next stage review final report. Cm 7432. Gateway ref. 10106. London: The Stationery Office. 92 pp.

https://www.gov.uk/government/uploads/system/uploads/attachment_data/file/228836/7432.pdf 
Department of Health (2010) Delivering same sex accommodation: self assessment, delivery planning and assurance.

http://webarchive.nationalarchives.gov.uk/20130107105354/http://www.dh.gov.uk/prod_consum_dh/gr oups/dh_digitalassets/documents/digitalasset/dh_112178.pdf

Department of Health (2014) Positive and proactive care: reducing the need for restrictive interventions. Social Care, Local Government and Care Partnership Directorate. 43 pp.

https://www.gov.uk/government/uploads/system/uploads/attachment_data/file/300293/JRA_DoH_Guid ance_on_RP_web_accessible.pdf

Department of Health (2015) Mental Health Act 1983: code of practice. London: The Stationery

Office. https://www.gov.uk/government/publications/code-of-practice-mental-health-act-1983

Education Act (1996 c. 56) London: The Stationery Office.

http://www.legislation.gov.uk/ukpga/1996/56/section/19

Equality Act (2010 c. 15) London: The Stationery Office.

http://www.legislation.gov.uk/ukpga/2010/15/contents

Family Law Reform Act (1969 c. 46) London: The Stationery Office.

http://www.legislation.gov.uk/ukpga/1969/46/contents

Fernandez, E., Perez, R., Hernandez, A., Tejada, P., Arteta, M. and Ramos, J. T. (2011) Factors and mechanisms for pharmacokinetic differences between pediatric population and adults.

Pharmaceutics. 3(1): 53-72. doi:10.3390/pharmaceutics3010053

General Medical Council (2013) Good practice in prescribing and managing medicines and devices. GMC/GMPip/1214. http://www.gmc-uk.org/guidance/ethical_guidance/14316.asp

HM Treasury (2003) Every child matters. Cm 5860. London: The Stationery Office, 102 pp. https://www.education.gov.uk/consultations/downloadableDocs/EveryChildMatters.pdf

Health \& Social Care Act (2012 c. 7) London: The Stationery Office.

http://www.legislation.gov.uk/ukpga/2012/7/contents

Human Rights Act (1998 c. 42) London: The Stationery Office.

http://www.legislation.gov.uk/ukpga/1998/42/contents

Kane, S. (2008) Managing the transitions from adolescent psychiatric in-patient care: toolkit. London: National Children's Bureau. 109 pp. http://www.ncb.org.uk/media/708733/mtra_lo-res.pdf

Mental Capacity Act (2005 c. 9) London: The Stationery Office.

http://www.legislation.gov.uk/ukpga/2005/9/contents

Mental Health Act (1983 c. 20) London: The Stationery Office. http://www.legislation.gov.uk/ukpga/1983/20/contents

Mental Health Act (2007 c. 12) London: The Stationery Office. http://www.legislation.gov.uk/ukpga/2007/12/contents 
NAPICU (2014) National minimum standards for psychiatric intensive care in general adult services. NAPICU. 75 pp. http://napicu.org.uk/wp/develop-your-practice/national-minimum-standards/

NDTi (2012) Reasonably adjusted? Mental health services and support for people with autism and people with learning disabilities. Bath: National Development Team for Inclusion.

http://www.ndti.org.uk/uploads/files/NHS_Confederation_report_Submitted_version.pdf

NHS England (2013) 2013/14 NHS standard contract for Tier 4 child and adolescent mental health services (CAMHS): general adolescent services. C07/S/a. http://www.england.nhs.uk/wpcontent/uploads/2013/06/c07-tier4-ch-ado-mh-serv.pdf

NHS England (2014) Child and adolescent mental health services (CAMHS) Tier 4 report. Gateway ref. 01891. http://www.england.nhs.uk/wp-content/uploads/2014/07/camhs-tier-4-rep.pdf

NHS England (2015) Monthly delayed transfer of care sitreps definitions and guidance. Version 1.08. NHS England. Gateway ref. 1865. http://www.england.nhs.uk/statistics/wpcontent/uploads/sites/2/2013/04/Monthly-Sitreps-Definitions-DTOC-v1.08.pdf

NHS Executive (2000) Safety, privacy and dignity in mental health units: guidance on mixed sex accommodation for mental health services. London: Department of Health. 26 pp.

http://webarchive.nationalarchives.gov.uk/20130107105354/http://www.dh.gov.uk/en/Publicationsands tatistics/Publications/PublicationsPolicyAndGuidance/DH_4007095

NICE (2013) Psychosis and schizophrenia in children and young people: recognition and management. NICE CG155. 56 pp. http://www.nice.org.uk/Guidance/CG155

NICE (2014) Safe staffing for nursing in adult inpatient wards in acute hospitals. NICE SG1. 61 pp. http://www.nice.org.uk/sg1

NICE (2015a) Violence and aggression: short-term management in mental health, health and community settings. NICE NG10. 643 pp. https://www.nice.org.uk/guidance/ng10

NICE (2015b) Medicines optimisation: the safe and effective use of medicines to enable the best possible outcomes. NICE NG5. 47 pp. https://www.nice.org.uk/guidance/ng5

Nolan, J. P. (2010) Resuscitation guidelines. Resuscitation Council (UK). 157 pp.

https://www.resus.org.uk/resuscitation-guidelines/

Ofsted (2013) The framework for school inspection. http://www.ofsted.gov.uk/resources/120100

P v Cheshire West and Chester Council (2014) UKSC 19.

$\operatorname{Re} \mathbf{D}(2015)$ EWHC 922 (Fam).

Resuscitation Council (UK) (2014) Quality standards for cardiopulmonary resuscitation practice and training: mental health - inpatient care. London: Resuscitation Council (UK).

https://www.resus.org.uk/quality-standards/mental-health-inpatient-care-quality-standards/

RK v BCC et al. (2011) EWCA Civ 1305. 
Royal College of Nursing (2014) Children and young people's mental health - every nurse's business: RCN guidance for nursing staff. London: Royal College of Nursing. 11 pp.

http://www.rcn.org.uk/_data/assets/pdf_file/0005/587615/004_587_WEB.pdf

Social Work (Scotland) Act (1968 c. 49) London: The Stationery Office.

http://www.legislation.gov.uk/ukpga/1968/49/contents

Thompson, P. and Clarke, H. (2013) Service standards. Seventh edition. Royal College of

Psychiatrists. CCQ1113. http://www.rcpsych.ac.uk/PDF/QNIC\%20Standards\%202013.pdf

Vitiello, B., Correll, C., van Zwieten-Boot, B., Zuddas, A., Parellada, M. and Arango, C. (2009)

Antipsychotics in children and adolescents: increasing use, evidence for efficacy and safety concerns.

European Neuropsychopharmacology. 19(9): 629-635. doi:10.1016/j.euroneuro.2009.04.008

Wagner, R. and Harter, J. K. (2006) 12: The elements of great managing. Gallup Press, 237 pp. 


\section{Appendix 1. Additional resources}

The following list is not exhaustive, but provides suggestions for resources that may be helpful for the effective implementation of this document.

\section{A1.1. General}

\section{Quality Network for Inpatient CAMHS (QNIC)}

Developed following the National Inpatient Child and Adolescent Psychiatry Study (NICAPS), the Quality Network for Inpatient CAMHS (QNIC) aims to demonstrate and improve the quality of inpatient CAMHS through a system of review against the QNIC service standards. The network facilitates the sharing of information from central sources to local services and sharing of best practice. Accreditation is also available to services meeting enough of the standards. The eighth edition of the QNIC service standards is due to be published in October 2015. http://www.qnic.org.uk/ http://www.rcpsych.ac.uk/workinpsychiatry/qualityimprovement/qualityandaccreditation/childandadoles cent/inpatientcamhsqnic/qnicrom.aspx

\section{National Minimum Standards for Psychiatric Intensive Care in General Adult Services}

Guidance on psychiatric intensive care for adult services produced by NAPICU in 2014. http://napicu.org.uk/wp/develop-your-practice/national-minimum-standards/

\section{Working Together to Safeguard Children: A guide to inter-agency working to safeguard and promote the welfare of children}

Statutory guidance on making arrangements to safeguard and promote the welfare of children under section 11 of the Children Act 2004 (2007):

http://media.education.gov.uk/assets/files/pdf/w/working\%20together.pdf

\section{A1.2. Risk management}

\section{Structured Assessment of Violence Risk in Youth (SAVRY)}

Tool for use in intervention planning and ongoing progress monitoring:

http://www4.parinc.com/Products/Product.aspx?ProductID=SAVRY

http://www.annarbor.co.uk/index.php?main_page=index\&cPath=416_419_189/ 


\section{A1.3. Outcome measures}

\section{Beck Depression Inventory}

There is a youth version for use up to 16 years, and an adult version for 16 years and above: http://www.beckinstitute.org/beck-inventory-and-scales/

Jolly, J., Arruffo, J., Wherry, J. and Livingston, R. (1993) The utility of the Beck anxiety inventory with inpatient adolescents. Journal of Anxiety Disorders. 7(2): 95-106. doi:10.1016/08876185(93)90008-9

Kashani, J., Sherman, D., Parker, D. and Reid, J. (1990) Utility of the Beck Depression Inventory with clinic-referred adolescents. Journal of the American Academy of Child \& Adolescent Psychiatry. 29(2): 278-282. doi:10.1097/00004583-199003000-00018

\section{Beck Hopelessness Scale}

Measures negative attitudes about the future:

http://www.pearsonclinical.com/psychology/products/100000105/beck-hopelessness-scale-bhs.html

\section{CHI Experience of Service Questionnaire (CHI ESQ)}

Developed by the Commission for Health Improvement (now the Health Care Commission) as a means of measuring service satisfaction in CAMHS. It was originally used as an anonymous measure for one-off audits of service delivery, but the CAMHS Outcome Research Consortium (CORC) recommends that it be used routinely with other core measures so that a family's experiences with the service can be linked to the young person's difficulties and symptom reduction.

http://www.corc.uk.net/wp-content/uploads/2013/10/ESQ-Info.pdf

\section{Children and Young People's IAPT}

The Children and Young People's Improving Access to Psychological Therapies programme (CYP IAPT) is a service transformation programme delivered by NHS England that aims to improve existing Child and Adolescent Mental Health Services (CAMHS) working in the community. The programme works to transform services provided by the NHS and partners from Local Authority and Third Sector that together form local area CAMHS Partnerships. It is different to Adult IAPT in that it does not create standalone services.

http://www.cypiapt.org/children-and-young-peoples-project 


\section{Children's Global Assessment Scale (CGAS)}

Rates the general functioning of children under the age of 18; an adaptation of the Adult Global Assessment Scale:

https://www.rcpsych.ac.uk/docs/CGAS\%20tool.doc

https://www.rcpsych.ac.uk/pdf/CGAS\%20Ratings\%20Guide.pdf

Shaffer, D., Gould, M. S., Brasic, J., Ambrosini, P., Fisher, P. and Aluwahlia, S. (1983) A

Children's Global Assessment Scale (CGAS). Archives of General Psychiatry. 40(11): 1228-1231.

doi:10.1001/archpsyc.1983.01790100074010

\section{Children's Obsessive Compulsive Inventory (ChOCI)}

Shafran, R., Frampton, I., Heyman, I., Reynolds, M., Teachman, B. and Rachman, S. (2003) The preliminary development of a new self-report measure for OCD in young people. Journal of Adolescence. 26(1): 137-142. doi:10.1016/S0140-1971(02)00083-0

Depression in Children and Young People: Identification and management in primary, community and secondary care

NICE Guideline 28; includes a summary information for the parents and carers:

http://www.nice.org.uk/guidance/cg28/informationforpublic

\section{Eating Disorders Questionnaire (EDE-Q)}

A self-report version of the Eating Disorder Examination (EDE):

https://www.rcpsych.ac.uk/pdf/EDE-Q.pdf

Fairburn, C. and Beglin, S. (2008) Eating disorder examination. In: Fairburn, C. (ed.). Cognitive behavior therapy and eating disorders. Guilford Press, New York, pp. 265-308.

\section{HoNOSCA}

Health of the Nation Scales for the Children and Adolescents (HoNOSCA):

https://www.rcpsych.ac.uk/pdf/glossary.pdf

https://www.rcpsych.ac.uk/PDF/HoNOSCA\%20Score\%20Sheet.pdf

Gowers, S., Bailey-Rogers, S. J., Shore, A. and Levine, W. (2000) The Health of the Nation Outcome Scales for Child and Adolesent Mental Health (NoNOSCA). Child Psychology \& Psychiatry Review. 5(2): 50-56. doi:10.1111/1475-3588.00285 
Motivational Stages of Change for Adolescents Recovering from an Eating Disorder (MSCARED)

A questionnaire designed to assess readiness to change in adolescents with eating disorders.

Gusella, J., Butler, G., Nichols, L. and Bird, D. (2002) A brief questionnaire to assess readiness to change in adolescents with eating disorders: its applications to group therapy. European Eating Disorders Review. 11(1): 58-71. doi:10.1002/erv.481

\section{QNIC ROM}

QNIC offers a routine outcome measurement service to all its members. QNIC ROM supports services to collect data and analyses the data to produce local service reports. National aggregated reports are also produced annually to allow benchmarking. Members gather data on a wide range of measures including: HoNOSCA (see above); CGAS (see above); Strengths and Difficulties Questionnaire (see below); EDE-Q (see above); diagnostic specific tools (e.g. Beck Hopelessness Scale). QNIC ROM is available for free to members of QNIC.

http://www.rcpsych.ac.uk/workinpsychiatry/qualityimprovement/qualityandaccreditation/childandadoles cent/inpatientcamhsqnic/qnicrom.aspx

\section{State-Trait Anxiety Inventory for Children (STAIC)}

Two 20-item scales that measure state and trait anxiety in children between the ages of 8 and 14:

http://www.mhs.com/product.aspx?gr=edu\&prod=staic\&id=overview\#top

\section{Strengths and Difficulties Questionnaire}

A behavioural screening questionnaire about 3-16 year olds (Goodman, 1997; Goodman et al. 1998)

http://www.sdqinfo.com/py/sdqinfo/b3.py?language=Englishqz(UK)

Goodman, R. (1997) The Strengths and Difficulties Questionnaire: a research note. Journal of Child Psychology \& Psychiatry. 38: 581-586.

Goodman, R., Meltzer, H., Bailey, V. (1998) The Strengths and Difficulties Questionnaire: a pilot study on the validity of the self-report version. European Child \& Adolescent Psychiatry. 7: 125-130. 


\section{A1.4. Education}

\section{Alternative provision}

Statutory guidance for local authorities, headteachers and governing bodies of all educational settings providing alternative provision.

https://www.gov.uk/government/publications/alternative-provision

\section{The Framework for School Inspection}

Ofsted guidance document.

http://www.ofsted.gov.uk/resources/120100

\section{Joint Council for Qualifications}

An organisation whose members comprise the seven largest providers of qualifications in the UK. It provides common administrative arrangements for examinations, and should be contacted regarding registration to become a registered examination centre.

http://www.jcq.org.uk

\section{A1.5. Patient \& carer information}

\section{HeadMeds}

This interactive website is specifically designed for young people by YoungMinds. It brings together general information about psychiatric medication and illnesses that young people may experience.

http://www.headmeds.org.uk/

\section{Headspace}

Accessible website on meditation.

https://www.headspace.com/

\section{Mindful}

Information on mindfulness, a mind-body approach to well-being to reduce stress and anxiety. http://bemindful.co.uk/ 


\section{Puzzledout}

A project to help young people and mental health services to work together to transform the way that services are provided. It provides an accessible platform for young people to speak about their experience of mental health services, covering the whole of England.

http://www.puzzledout.com/

\section{YoungMinds}

A UK charity that works to improve the emotional well-being and mental health of children and young people. Their website brings together a range of general information and their resources for young people, parents and professionals.

http://www.youngminds.org.uk

Parent helpline: 08088025544

\section{A1.6. Managing emergencies}

\section{Positive and Proactive Care: Reducing the need for restrictive interventions}

Policy document on the use of restrictive interventions for health care providers, family and/or carers

https://www.gov.uk/government/uploads/system/uploads/attachment_data/file/300293/JRA_DoH_Guid ance_on_RP_web_accessible.pdf

Quality Standards for Cardiopulmonary Resuscitation Practice and Training: Mental health - inpatient care

https://www.resus.org.uk/quality-standards/

\section{A1.7. Prescribing guidance}

\section{Attention deficit hyperactivity disorder}

NICE guideline on the diagnosis and management of ADHD in children, young people and adults. Summary information for the public:

http://www.nice.org.uk/guidance/cg72/informationforpublic 


\section{British Formulary for Children}

All healthcare professionals involved with the use of medicines should be familiar with the BNFc and up to date with relevant significant changes. This contains essential information for the safe effective and appropriate use of medicines in young people, from prescribing and monitoring, to supply and administration. The prescribing notes in the BNFc provide an overview of the drug management of common conditions, and facilitate rapid appraisal of treatment options. Advice issued by NICE is usually integrated within BNFc prescribing notes. http://www.bnf.org

\section{Electronic Medicines Compendium}

Collation of SPCs or 'licences' for medicines, and the manufacturers' information leaflets for patients:

http://www.medicines.org.uk/emc/

\section{General Medical Council (GMC) Prescribing Guidance}

Prescribing guidance is available online:

http://www.gmc-uk.org/guidance/ethical_guidance/14331.asp

\section{Medicines and Healthcare Products Regulatory Agency (MHRA)}

Provides further information about licensing of medicines:

http://www.mhra.gov.uk/Howweregulate/Medicines/index.htm

\section{Psychosis and Schizophrenia in Children and Young People}

NICE guideline on recognition and management of psychosis and schizophrenia. Summary information for the public:

http://www.nice.org.uk/guidance/cg155/informationforpublic 


\section{Appendlix 2. Additional legal information \& definitions}

\section{A2.1. Statutory rights}

A2.1.1. The Family Law Reform Act 1969 (Section 8(1)) states that 16 and 17 year olds can consent to medical treatment. This position was given further power under the Mental Capacity Act 2005 which conferred the right to refuse treatment for those young people deemed to have the capacity to make such a decision.

\section{A2.2. Parental responsibility $\&$ care orders}

A2.2.1. Parental responsibility usually, but not always, refers to the powers and duties of the parents of the young person in relation to decisions and general welfare. A mother automatically has parental responsibility for her child from birth, unless the child has been adopted by another. The father has parental responsibility if he was married to the mother at the point of birth, or if he subsequently acquires it, through registration, court order, or subsequent marriage to the mother. If the young person was born after 1 December 2003 (4 May 2006 in Scotland) the father will also have parental responsibility if named on the birth certificate.

A2.2.2. Step-parents may acquire parental responsibility through an agreement or court order. Other individuals may acquire parental responsibility through a Residence Order (Section 12(2) of the Children Act 1989), by adoption, or by being appointed as a guardian (this is not the same as a Guardian under Section 7 of the MHA 1983).

A2.2.3. Under Section 31 of the Children Act (the 'care order'), a local authority, by order of the court, acquires parental responsibility for a young person (delineated under Section 33(3)(a)) which it shares with the parents for the duration of the care order. The court can determine the extent to which a parent or guardian of the child may meet their parental responsibility in order to safeguard the child's welfare (Section 33(3)(b)). The local authority does not acquire parental responsibility if the young person has been voluntarily accommodated by them.

A2.2.4. Where a young person is subject to a care order under Section 31 of the Children Act 1989, or where parental rights are vested in the local authority under Section 16 of the Social Work (Scotland) Act 1968, the local authority will be deemed to be the nearest relative in preference to anyone (unless they are married or have a civil partner). If a guardian has been appointed for a young person under the age of 18 , or a residence order is in force, that guardian is deemed to be the nearest relative. 
A2.2.5. Although young people may acquire rights to give consent for themselves as they grow older, people with parental responsibility for a young person retain certain rights to give consent on the young person's behalf until the young person reaches the age of 18 . Until the age of 16 , both the child and a person with parental responsibility have the right to give consent to the child's treatment. In law, health professionals only need the consent of one appropriate (competent/capacitated) person before providing treatment.

\section{A2.3. Capacity \& competence}

A2.3.1. In this context, the terms 'capacity' and 'competence' refer to the aptitudes and abilities of young people to make independent decisions. The Mental Capacity Act 2005 does not apply to anyone under the age of 16 so the term 'capacity' is misleading for a child and should not be used. However, children may either have or lack Gillick competence.

\section{A2.4. Gillick competence}

A2.4.1. Young people develop at different speeds and the most commonly quoted case in relation to this concept is that of Gillick v West Norfolk and Wisbech AHA [1985] 1 AC 112. The notion of a level of competence at which a young person could make decisions was made concrete by this case. Gillick competence refers to a young person having, in the words of Lord Scarman in this case, 'sufficient understanding and intelligence to understand fully what is proposed'. Children under 16 are afforded rights to consent and refuse treatment or admission, instruct their solicitors and so forth.

A2.4.2. It is noteworthy that in case law, parental responsibility has been used to override 'competent' consent (Re R (A Minor) (Wardship: Medical Treatment) [1992] 1 FLR $190)$ ) in the case of a 15 year old, and 'capacitated' refusal (Re W (A Minor) (Medical Treatment: Court's Jurisdiction) [1992] 4 All ER 627) in the case of a 16 year old. It should be noted that this was prior to the introduction of the Mental Capacity Act 2005 which has changed the position for 16 and 17 year olds (who cannot now have their capacitated decision overruled by parental responsibility). 



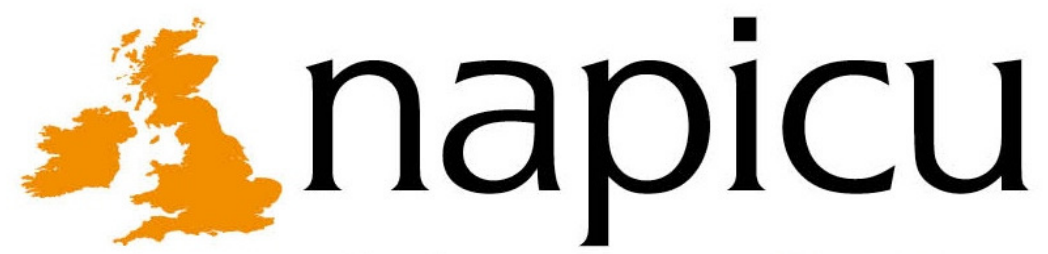

national association of psychiatric intensive care $\mathcal{E}$ low secure units

\section{NAPICU Administration Office}

Scottish Enterprise Technology Park

$2^{\text {nd }}$ Floor, Nasmyth Building

60 Nasmyth Avenue

East Kilbride

G75 OQR

Tel: 01355244585

Fax: 01355249959

Email: info@napicu.org.uk

Web: www.napicu.org.uk 